This is an informal report intended primarily for internal or limited external distribution. The opinions and conclusions stated are those of the author and may or may not be those of the laboratory.
UCID - 16666

RECEIVED BY TIC MAR 101975

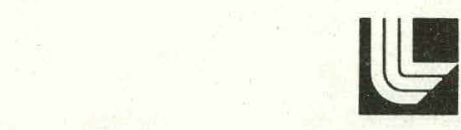

I_AWRENCE L_IVERMORE LABORATORY

University of California/Livermore, California

\title{
FAULT TREE ANALYSIS OF THE EMERGENCY \\ POWER SYSTEM OF TWO LIGHT-WATER \\ NUCLEAR POWER REACTORS
}

J. E. Wells

J. W. Savage

January 29, 1975

\begin{abstract}
This report was prepared as an account of work sponsored by the United States Government. Neither the United States nor the United States Energy the United States nor the United States Energy
Research and Development Administration, nor any of their employees, nor any of their contractors, subcontractors, or their employees, makes any warranty, express or implied, or assumes any legal liability or responsibility for the accuracy, completeness or usefulness of any information, apparatus, product or or usefulness of any information, apparatus, product or
process disclosed, or represents that its use would not infringe privately owned rights.
\end{abstract}




\section{DISCLAIMER}

This report was prepared as an account of work sponsored by an agency of the United States Government. Neither the United States Government nor any agency Thereof, nor any of their employees, makes any warranty, express or implied, or assumes any legal liability or responsibility for the accuracy, completeness, or usefulness of any information, apparatus, product, or process disclosed, or represents that its use would not infringe privately owned rights. Reference herein to any specific commercial product, process, or service by trade name, trademark, manufacturer, or otherwise does not necessarily constitute or imply its endorsement, recommendation, or favoring by the United States Government or any agency thereof. The views and opinions of authors expressed herein do not necessarily state or reflect those of the United States Government or any agency thereof. 


\section{DISCLAIMER}

Portions of this document may be illegible in electronic image products. Images are produced from the best available original document. 


\title{
FAULT TREE ANALYSIS OF THE EMERGENCY \\ POWER SYSTEM OF TWO LIGHT-WATER \\ NUCLEAR POWER REACTORS
}

\begin{abstract}
The emergency power system of a nuclear power reactor is designed to provide the necessary power for startup, operation, shutdown, and other station requirements. During a loss-of-coolant accident (LOCA) this emergency power system provides the required amount of power to mitigate the effects of transients and accidents. This report addresses the problem of having "insufficient power" available to the Enginee red Safety Features (ESF) during LOCA. Fault tree analysis techniques, both qualitative and quantitative, were used to obtain this information. The results of these analyses are described.
\end{abstract}

\section{INTRODUCTION}

The principal function of the emergency power system of a nuclear power reactor is to mitigate the effects of transients and accidents. 'l'he probability of having "insufficient power" for the emergency power system of a boiling-water reactor (BWR) and a pressurized-water reactor ( $P W R$ ) is the problem that is addressed in this report. As used here, the term "insufficient power" refers to any state of the emergency. power system that inhibits the Engineered Safety Feature (ESF) system's operability during the course of a loss-of-coolant accident (LOCA).

This analysis is part of an AEC Reactor Safety Study, WASH-1400, ${ }^{1}$ which was directed by Dr. Norman Rasmussen of the Massachusetts Institute of Technology. The study was undertaken to assess accident risks in U. S. commercial nuclear power plants. Because of the expertise available at LLL in fault tree analysis, the Laboratory was asked to participate in the study to assess the probability of eme rgency power system failure.

This report summarizes the results of the fault tree analyses used to determine the failure modes and component dependencies that could result in insufficient power. Applicable failure statistics were subsequently used to quantify the fault trees, which were developed for both the BWR and the PWR. These two fault trees include subtrees that depict insufficient power for each emergency bus. The subtrees do not analyze failures of actual ESF loads, but the effects of such failure on the emergency power system are included.

The following individuals at Lawrence Livermore Laboratory participated in the emergency power system analysis: Howard Lambert, Bill Miller, Jack Savage, Don Thompson, and Jim Wells. We would also like to acknowledge the assistance provided by Dr. John Mansfield of Scientific Applications, Inc. in the quantative 
analysis portion of this report, and the useful comments provided by Nat Villalva of the AEC.

\section{SUMMARY OF RESULTS}

The probability of being in a state of insufficient power has been computed for two discrete cases: (1) at the inception of LOCA, and (2) subsequent to LOCA. The median estimate of insufficient power at LOCA $\left(Q_{\text {med }}\right)$ as determined by the $B W R$. analysis is:

$$
Q_{\text {med }}=10^{6} \text { per demand. }
$$

The associated $90 \%$ confidence bounds on this median estimate arc:

$$
\begin{aligned}
& Q_{\text {lower }}=10^{-7} \text { per demand, } \\
& Q_{\text {upper }}=10^{-5} \text { per demand. }
\end{aligned}
$$

The major contrihutions to insufficient power at LOCA are the coincident loss of both offsite power sources and the onsite power system's failure to provide sufficient power to maintain ESF system operability.

The median estimates of insufficient power subsequent to LOCA, given success at LOCA, and the associated $90 \%$ confidence bounds for various times after LOCA are given in Table 1.

Table 1. Estimates of insufficient power subsequent to LOCA for BWR.

\begin{tabular}{cccc}
$\begin{array}{c}\text { Time } \\
\text { after LOCA }\end{array}$ & \multicolumn{2}{c}{$90 \%$ bounds } & Q \\
\hline $1 \mathrm{hr}$ & $<1.0 \times 10^{-8}$ & - & Lower \\
$24 \mathrm{hr}$ & $4.0 \times 10^{-7}$ & $4.0 \times 10^{-6}$ & - \\
$4 \mathrm{mo}$ & $6.0 \times 10^{-6}$ & $6.0 \times 10^{-5}$ & $4.0 \times 10^{-8}$ \\
$9 \mathrm{mo}$ & $7.5 \times 10^{-6}$ & $7.5 \times 10^{-5}$ & $6.0 \times 10^{-7}$ \\
\hline
\end{tabular}

The maximum allowable outage time increases with time after LOCA; therefore, the cumulative probability of insufficient power subsequent to LOCA increases less rapidly with time than would otherwise be the case. The dominant contributors to insufficient power subsequent to LOCA are: (1) loss of both offsite power sources for a critical duration of time, and (2) failure of the four diesel generator sets to start, or subsequent failure of the four diesel generator sets before offsite power is restored.

The median estimate of insufficient power at LOCA $\left(Q_{\text {med }}\right)$ as determined by the PWR analysis is: 


$$
Q_{\text {med }}=10^{-5} \text { per demand. }
$$

The associated $90 \%$ confidence bounds on this median estimate are:

$$
\begin{aligned}
& Q_{\text {lower }}=10^{-6} \text { per demand, } \\
& Q_{\text {upper }}=10^{-4} \text { per demand. }
\end{aligned}
$$

The major contributors to insufficient power at LOCA are the coincident loss of the offsite sources and failure of both diesel generator sets.

The median estimates of insufficient power subsequent to LOCA, given success at LOCA, and the associated $90 \%$ confidence bounds for various times after LOCA are given in 'lable 2.

Table 2. Estimates of insufficient power subsequent to LOCA for PWR.

\begin{tabular}{cccc}
\hline $\begin{array}{c}\text { Time } \\
\text { after LOCA }\end{array}$ & $Q_{\text {med }}$ & Upper & Lo\% bounds \\
\hline $1 \mathrm{hr}$ & $2.0 \times 10^{-7}$ & $2.0 \times 10^{-6}$ & $2.0 \times 10^{-8}$ \\
$24 \mathrm{hr}$ & $5.2 \times 10^{-6}$ & $5.2 \times 10^{-5}$ & $5.2 \times 10^{-7}$ \\
$4 \mathrm{mo}$ & $7.5 \times 10^{-5}$ & $7.5 \times 10^{-4}$ & $7.5 \times 10^{-6}$ \\
$9 \mathrm{mo}$ & $7.6 \times 10^{-5}$ & $7.6 \times 10^{-4}$ & $7.6 \times 10^{-6}$ \\
\hline
\end{tabular}

\section{SYSTEM DESCRIPTION}

The electrical power distribution system consists of the emergency power and balance of plant (BOP) systems. Since the latter two systems have several interfaces, a general overview of the electrical system is prescnted.

The emergency power system is principally for safety. It provides reactor protection power for safe shutdowns and ESF power to mitigate the effects of transients and accidents. In contrast, the BOP system provides power to those loads that, nominally, have no safety implications, but are required for continuous plant operation and general purposes. The major constituents of the electrical power system are shown in Appendices A and B (for the BWR, see Figs. A-1 and A-2; for the PWR, see Figs. $B-1$ and $B-2$ ).

The BWR being discussed is Unit 2 of a three-unit nuclear power facility. The Unit 3 main generator is included in both Figs. A-1 and A-2 to show its relation to the emergency power systcm of Unil 2. The Unit 3 emergency power system has been omitted because, except for the components common to both units (see. Figs. A-3 and $A-4$ ), it has no effect on the emergency power system of Unit 2. During normal BWR operation, the Unit 2 main generator provides power to the $500-\mathrm{kV}$ south substation. The Unit 2 main generator also provides power to the $13.2-\mathrm{kV}$ BOP 
system through the unit auxiliary transformer, which lowers the generated voltage from 22 to $13.2 \mathrm{kV}$. In no case does the output of the Unit 2 main generator directly serve the emergency power system. In contrast, under certain conditions described later, the BOP loads are served from the offsite power sources, the preferred source of power for the emergency power system.

The PWR analyzed is Unit 1 of a two-unit facility. During normal PWR operation, the Unit 1 main generator provides power to the $230-\mathrm{kV}$ substation through the main transformers, which raise the voltage from 22 to $230 \mathrm{kV}$. In addition, the Unit 1 main generator provides power to the BOP loads during normal operation by an extension of the $22-\mathrm{kV}$ network, which lowers the voltage through the station transformers to $4.16 \mathrm{kV}$. In no case, as noted for the BWR, does the output of the Unit 1 main generator directly serve the emergency power system. As in the BWR casc, the BOP loads can be served from the offsite power sources.

During BWR and PWR plant start up, hot standby, or shutdown operations, ac power for both the BOP and the emergency power systems is provided by the power grid via the $230-\mathrm{kV}$ and/or the $500-\mathrm{kV}$ switchyard. Under normal conditions, the emergency power system is served from two offsite sources, each capable of supplying the total emergency rcquirements of both unils.

In the event of a LOCA in the BWR, the following sequences would normally occur. The turbine generator would trip, and the $500-\mathrm{kV}$ breakers 215 and 225 would open. In addition, breakers 0101 and 0214 (on 13.2-kV buses $20 \mathrm{~A} 01$ and $20 \mathrm{A02}$ ) would open, the reby causing the loss of all BOP loads. For the PWR case, both the turbine generator and the $230-\mathrm{kV}$ breakers G102 and G1T240 would trip. Breaker 15A2, 15B2, and $15 \mathrm{C} 2$ would also open, thereby dropping the BOP loads they normally feed.

Upon such loss, the se loads for both the BWR and PWR would be automatically transferred to the offsite power system as described for the shutdown case. The LOCA would generate an ESF signal, activating the ESF systems. Normally, the ESF systems would be powered from the offsite sources. The ESF signal would also start the diesel generators; if offsite power is lost, the diesel generators would serve the ESF loads. If the offsite power is lost coincident with or during the course of a LOCA, power will not be available for the BOP loads.

For both the BWR and PWR, two offsite powcr sources are provided, each capable of serving all the emergency power requirements. Their onsite power systems consist of an ac system (diesel generators as a back-up source of ac power for the ESF loads) and a dc system.

\section{Onsite ac Power System}

In the BWR case, four diesel-generator sets are available to provide onsite ac power if offsite ac power is lost. The output of each diesel-generator set is shared between both Units 2 and 3, and the combined output of three of the four sets can accommodate the loads required to mitigate the affects of LOCA on one unit and the 
safe shutdown requirements of the other. The installed capacity of this system can tolerate the loss of any diesel generator under the above load conditions. These diesel generators back up the offsite power system and are required only upon loss of both offsite sources.

In the PWR case, two diesel generator sources of ac power are provided for Unit 1, DG-1 and DG-3. DG-1 is dedicated to Unit 1; DG-3 can serve either Unit 1 or Unit 2 on a priority basis, but not both simultaneously. Priority is determined by the main generator unit, which generates a priority demand, such as a safety injection control signal, provided that offsite power is also lost. A third diesel generator, DG-2, is dedicated to Unit 2. The installed capacity of the system is sufficient to accommodate LOCA in one unit and safe shutdown requirements on the other with one diesel generator out of service.

\section{Onsite dc Power System}

Four sources of onsite dc power, consisting of four $125-\mathrm{V}$ batteries and chargers, are provided for Unit 2 in the BWR. Each battery serves one $125-\mathrm{V}$ dc bus. In addition, the batteries are aligned to form two pairs, and each pair is connected in series to provide two sources of $250-\mathrm{V}$ dc power. Some Unit 3 loads are served from this system, and Unit 3 has an identical system that serves some Unit 2 emergency loads, as shown in Appendix A (see Fig. A-4).

The PWR dc system consists of two $125-\mathrm{V}$ batteries and charger systems, one for each redundant train. Each battery floats on its own $125-V$ dc bus with the normal load supplied by two battery charges, either of which can supply the regular noneme rgency load.

\section{Emergency Power Distribution System}

The BWR emergency power distribution system consists of four $4160-\mathrm{V}$ ac buses, four $480-\mathrm{V}$ ac load centers, fourteen $480-\mathrm{V}$ motor control centers, four $120 / 208-\mathrm{V}$ ac panels, two $250-\mathrm{V}$ dc buses and four $125-\mathrm{V}$ dc panels. This system is arranged in four redundant, but not completely independent channels, ZA, ZB, ZC, and ZD. These four channels are paired to form two rcdundant and electricilly independent divisions, as shown in Appendix A, Fig. A-1. If any one of the $4160-\mathrm{V}$ buses is lost, all ac power to its associated channel is also lost. Because of the importance of continuity of service to these buses, each is provided with three sources of power: two from the offsite power source, one of which is the normal source and the other an alternate source that assumes the load if the former fails, and an onsite source that assumes the load if both offsite sources fail. Therefore, if the normal offsite source fails, the affected bus is automatically lransferred to the alternate offsite source; if both offsite. sources fail, the onsite source (the diesel generators) automatically provides power to the bus within $13 \mathrm{sec}$ after loss of offsite power. 
The PWR emergency power distribution system consists of two redundant and basically independent trains, $A$ and $B$. Each train consists of a $4160-V$ ac bus, a $480-\mathrm{V}$ bus, two $480-\mathrm{V}$ motor control centers, and a $125-\mathrm{V}$ dc bus. If either of the $4160-\mathrm{V}$ ac buses is lost, all ac power to its associated train is also lost. Because of the importance of service continuity, both of these buses are provided with two sources of power: the offsite power source (the preferred source), and the onsite power source (the standby source provided by the diesel generator). If the preferred source is lost, the emergency source will start automatically and provide power to the affected $4160-\mathrm{V}$ ac bus.

\section{Protective Systems}

Both emergency power systems are provided with automatic protective devices. Differential relays protect major equipment, such as the diesel generator and transformers. Undervoltage relays insure continuity of service by tripping the preferred source of power upon a low-voltage condition, starting the diesel generator, and transferring the load to the diesel generator. Instantaneous overcurrent relays protect against short circuits. Time-delay overcurrent relays protect against cquipment malfunclions, such as a locked rotor condition or excess friction. The trip settings of the overcurrent relays are coordinated to minimize the effect of any failure on the overall power system. The relays are set so that the breaker that feeds a faulted circuit would be the first to trip, the reby confining the loss of power to the affected circuit. Indicating devices in the form of alarms and annunciators are also provided. Thus, if the automatic devices should fail, the operator may be able to take appropriate action via the manual control devices located in the control room or at the breaker panels.

\section{TECHNIQUE OF FAULT TRFE ANALYSIS}

Fault tree analysis is used to determine which faults or combinations of faults will result in a particular system failure. References 2 and 3 discuss the fault tree analysis method in more detail. The system failure of interest in this report,

"insufficient power exists on the emergency power bus," is known as the undesired, or top crent.

The undesired event, or failure condition for which the analysis is being made, must be carefully defined for a correct analysis to result. Because of its importance, defining the undesired event should be undertaken by several people knowledgeable of the system involved and given sufficient time for fully considering the definition.

Determining the degree of resolution required by the analysis is just as important as defining the undesired event. A fine degree resolution would require an extensive determination of the effect of small parts of the system, such as individual wires, terminals, bolts, nuts, relay or switch contacts, bearings, shafts, valves, pipes, insulators, or plugs. A coarser degree of resolution would allow the tree to 
be truncated or stopped at the level of relays, motors, pumps, engines, transformers, circuit breakers, amplifiers, regulators, generators, buses, and cooling towers.

It is also possible for the tree to be constructed with different branches requiring different degrees of resolution. The degree of resolution may be determined by the purpose of the analysis or the type of data available for use in quantifying the tree. It is necessary to spend adequate time and manpower for an independent review of the tree to assure completeness and accuracy.

Obtaining adequate data may be a problem equivalent to developing the fault tree. Here, again, planning should include adequate time and manpower for properly determining the extent to which the tree will be developed. Otherwise, unnecessary effort will be spent unproductively.

A fault tree analysis may be both qualitative and quantitative. A qualitative analysis is useful for design and performance review. The quantitative analysis can be used, if desired, to find and correct areas of inadequate performance by substituting components of improved reliability in optimal locations in the system. In most cases, once a tree has been developed to the desired degree of resolution to match the stated purpose and available quantitative data, it will be possible to produce a simplified "reduced tree" to clarify the qualitative aspects of the analysis, and make quantifcation easier.

Reducing the tree involves a combination of qualitative and quantitative considerations. It is often possible to combine many branches of a complex tree into a simple listing of single, double, or higher-order events. Quantitative considerations may make it possible to omit some combinations from the listing if the probability of occurrence is significantly low. It is attractive, but risky, to develop a reduced tree directly. If the problem is complex, the complete tree. must be developed to assure accuracy of reduction.

The analysis is accomplished by drawing a fault tree model using a logic symbol format to represent the power supply functions of the reactor's emergency powe $r$ system as they relate to the top event (see Ref's. 4-7). The following symbols (Fig. 1) were used to make up the fault tree models. The symbols are combined to form a fault tree, thus providing a complete system representation from which a functional analysis can be made.

An "AND" gate (Fig. 1a) requires that all inputs be satisfied before an output from it will occur. An "OR" gate (Fig. 1b) requires that only one or more inputs be satisfied before an output from it will occur.

A Matrix gate (Fig. 1C) is a form of an "AND" gate that requires a combination of inputs to occur. For example, given two lists of possible failures, $A$ and $B$, the undesired event will occur only if any one failure on list A is "ANDed" with any one failure on list $B$.

A Circle (Fig. 1d) represents a component primary failure sufficient to actuate the input to a gate. The term "component" is subject to definition to suit the case being analyzed, but in all cases it is the termination of a particular branch of the fault 
(a)

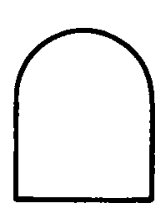

(b)

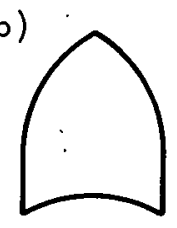

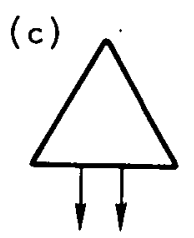
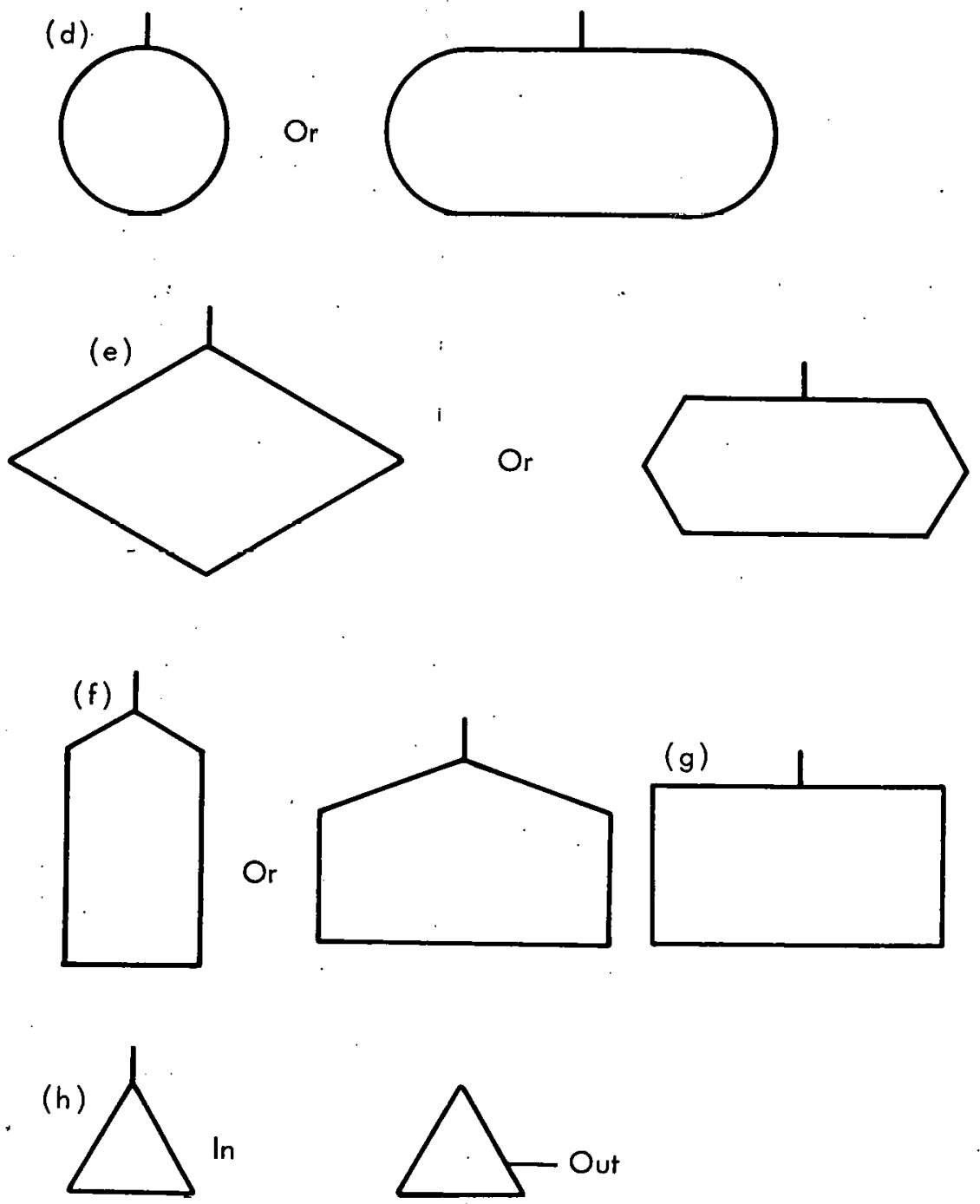

Fig. 1. Logic symbols for fault tree models. (a) AND gate. (b) OR gate. (c) Matrix gate. (d) Circles. (e) Diamonds. (f) Houses. (g) Rectangle.

(h) Triangles. 
tree, as determined by the desired degree of resolution of the analysis. This type of failure is known in the lite rature as a random failure. The rate of occurrence is said to be the generic failure rate for the failure mode in question. Circles represent components that may fail to perform their intended functions when needed.

A Diamond (Fig. 1e) is similar to a circle in that it represents a failure or abnormal occurrence sufficient to actuate an input to a gate, and is the termination of a particular branch of the tree. It differs, however, in that it represents a device, a subsystem, an open or short circuit wiring fault, a circuit discontinuity, a human action, or other event for which the analysis is truncated before the re are sufficient details developed for it to be represented by the additional tree branches that would ultimately end in primary fault circles. The desired degree of resolution dictates when a particular branch can be terminated in a diamond. Examples are a short circuit to a voltage source, operator error, and failures requiring limiting conditions so that a fault will result. Diamonds can also represent events considered incredible.

Houses (Fig. 1f) represent limiting conditions or contingencies. They provide the analyst with the capability of enabling or disabling any portion of the tree. Each condition can be enabled or disabled individually or simultaneously, depending on the conditions that exist in the analysis being conducted.

The Rectangle (Fig. 1 $\mathrm{g}$ ) is used to define an event that results from the logical operation of one or more events.

Finally, the Triangle (Fig. $1 \mathrm{~h}$ ) is used as a convenient symbol to allow the transfer of a branch of the fault tree.

Some examples of how these logic symbols can be used are given in Figs. 2 and 3 . As systems become mcre complex, other symbols describing conditions that exist become useful. These symbols will not be discussed here, however.

\section{ANALYSIS}

The fault tree was analyzed to determine the causes of insufficient power on each emergency bus. These individual subtrees were used as transfer inputs to the system trees whe re electric power is needed to operate required ESF equipment. The subtrees we re constructed in enough detail to determine single and double independent failures that could cause the undesired event. In many cases, assurance of independence required carrying the level of resolution down to individual components in control circuits.

\section{Definition of Undesired Event}

The undesired event for the loss of the emergency system in both PWR and BWR is termed "insufficient power." This term means any state of the emergency system that inhibits adequate ESF operability during a LOCA. The undesired event for the subtrees of the emergency buses is any condition that prevents the bus from distributing power to the ESF loads. 


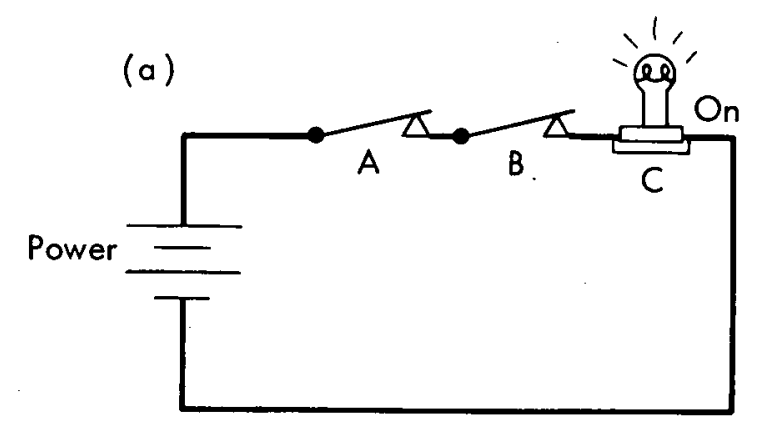

(b) :

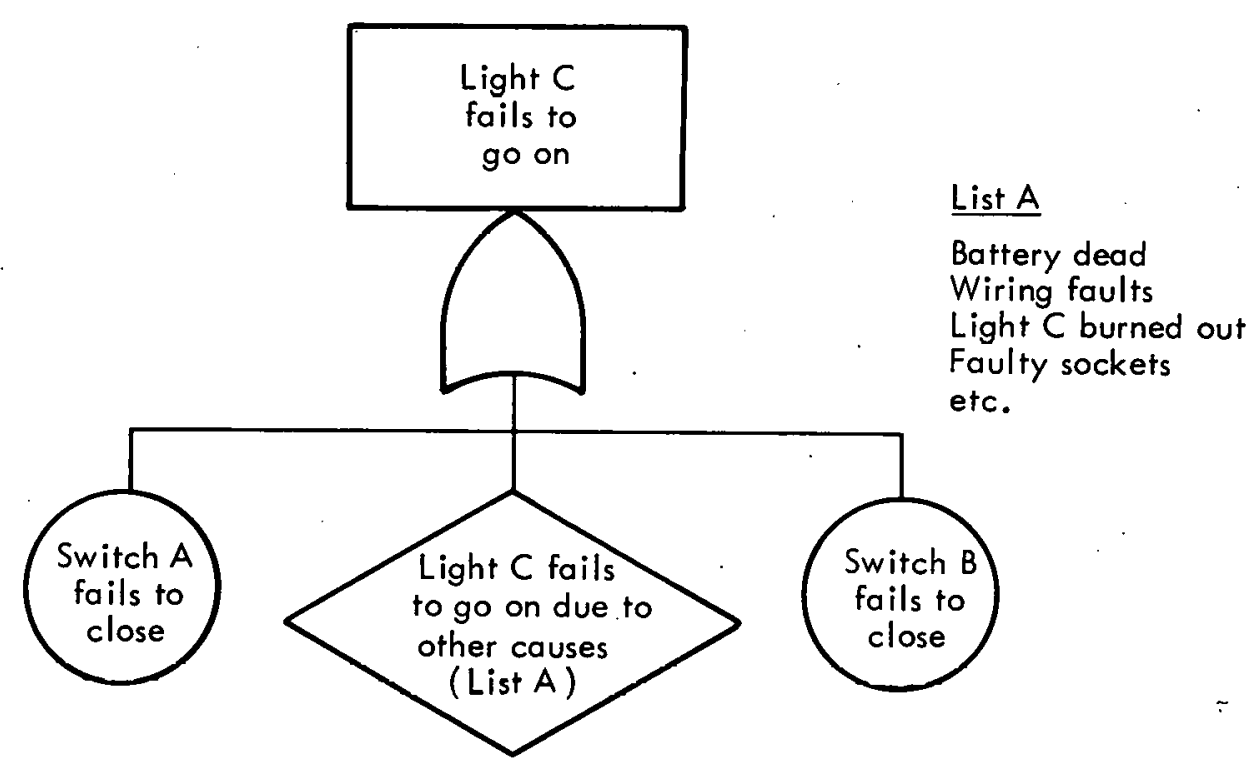

Fig. 2. Logic symbol format for exemplary power system. (a) Power system A. (b) Fault tree of system.A. 


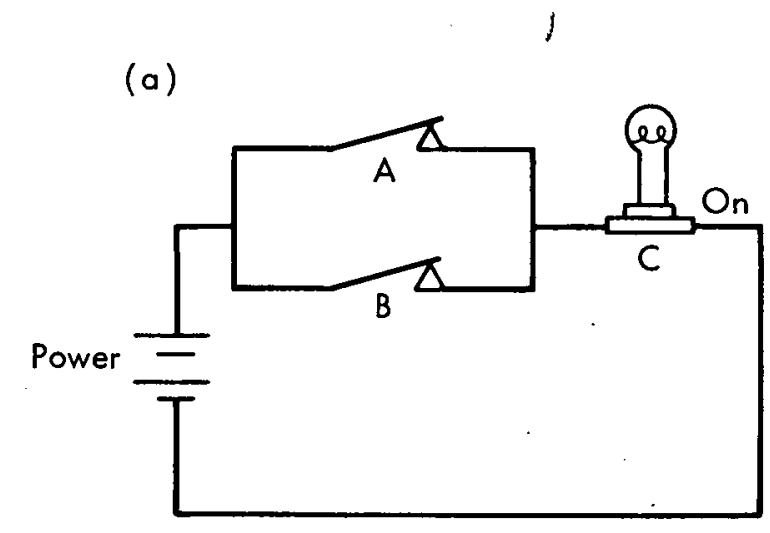

(b)

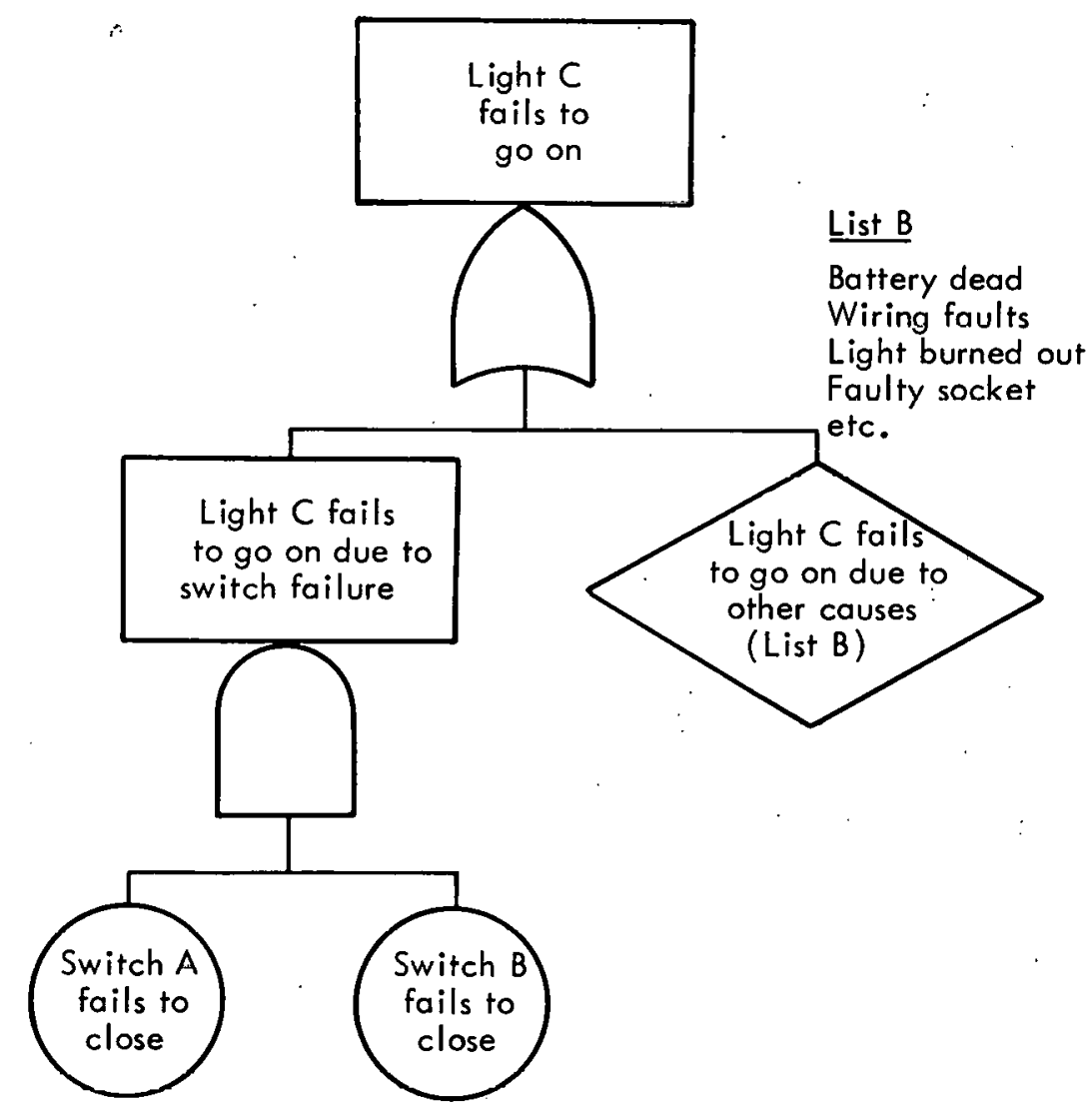

Fig. 3. Logic symbol format for exemplary power system. (a) Power system B. (b) Fault tree of system B. 
An event denoted as "total loss of electrical power" was defined in the BWR case as either the coincident loss of all of site and onsite ac power, or the coincident loss of offsite power and the critical station batteries (see Appendix C). An equivalent but undefined event was a major contributor to the "insufficient power" treetop of the PWR.

Analysis Assumptions

Three types of assumptions are used to construct a probabilistic evaluation of the emergency power system fault tree and subtrees: general assumptions, human interactions, andhardware assumptions. Unless otherwise noted, assumptions apply to both PWR and BWR.

General assumptions fall into the following categories.

1. All emergency buses are available immediately before LOCA. This assumption is based on the technical specifications requiring that the reactor be shutdown if an emergency bus is not available.

2. Only those events that appear in single- or double-cut sets are included in the fault trees of the individual buses of the emergency power system.

3. Nonemergency buses and loads that are isolated from the emergency power system by two or more circuit breakers are not potential fault sources to the emergency power system.

4. The possibility of losing both offsite and onsite power sources due to starting surges of the emergency system loads was concluded to exist, but not analyzed in detail because several independent failures are required for this event.

The human interactions that are assumed include,

1. No credit is taken for any operator action that may compensate for a failure during the first hour following LOCA.

2. For times greater than one hour after LOCA, credit is allowed for corrective operator actions provided the actions are relatively simple and do not require the operator to leave the control room.

3. For times greater than $10 \mathrm{hr}$ following LOCA, certain corrective actions that require the operator to leave the control room are permitted. These actions include simple operations such as resetting relays and closing or opening circuit breakers remote from the control room.

4. Credit is allowed at all times using a probabilistic basis of repair time for the diesel generators and the net. Beginning one month after LOCA, credit on the same basis is allowed for all other major electrical components.

More credit is allowed for human intervention as time progresses subsequent to LOCA, because the time required to begin core meltdown upon loss of electric power increases with time. For example, a dry core heatup will be initiated in about $30 \mathrm{sec}$ if power is lost shortly after a large LOCA, and in $20 \mathrm{~m}$ in if power is lost $10 \mathrm{hr}$ after the accident. 
Hardware assumptions are made for the high-voltage switchyard, the $4160-\mathrm{V}$ switchgear, the motor control centers, and the dc system. In the case of the BWR high-voltage switchyard,

1. The disconnects we re included as part of the circuit breakers.

2. Power is not supplied to bus 00A03 A through either bus U0A03B or $00 \mathrm{~A} 030$.

3. Power is not supplied to bus 00A04 through eithe $r$ bus 00A05 or 00A06.

For the PWR high-voltage switchyard,

1. The disconnects we re included as part of the circuit breakers.

2. If the $230-\mathrm{kV}$ brcakcrs G102 and G1T240 do not open in the event of a turbine trip caused by a large primary coolant pipe break, the main generator will run as a synchronous motor, and the windings of the genterator will heat and short in about $15 \mathrm{~min}$. Such a short will effeclively place a short circuit on buses 230-3 and 230-4 and will result in total loss of offsite power if breakers L202 and L102 do not clear the fault. If only breaker L202 does not clear, offsite power to Train " $\mathrm{A}$ " will be lost. Conversely, if only breaker L102 does not clear, offsite power to Train "B" will be lost.

3. If offsite power is lost to one of the two $34.5-\mathrm{kV}$ buses, it is assumed that tie breaker 56 will not automatically close to transfer power from one offsite source to the other.

Two assumptions are made for the BWR $4160-\mathrm{V}$ switchgear. First, the $4160-\mathrm{V}$ buse $00 A 19$ and 00A20 are normally supplied from their own offsite power source. Second, the $4160-V$ emergency buses, E12, E32, E22, and E42, can be energized from either offsite power source, but are normally connected as shown in Appendix A, Fig. A-3. In the PWR case, tie breaker $15 \mathrm{HI}$ is not installed in its cubicle.

In the motor control center, shorts on the dc side of the battery charger are also treated as shorts on the ac motor control center that feeds the charger; however, the current blocking characteristics of the rectifiers isolate the dc system from shorts on the ac side of the battery chargers.

Finally, three assumptions are made for the dc system:

1. The dc connected loads are assumed to be within the capabilities of the batteries such that dc voltage is adequate during the critical time period when dc control power is needed to perform the ESF functions.

2. A shurl un the ac side of the inverter is assumed to overload the dc bus, the reby lowe ring the dc voltage below acceptable levels.

3. The estimate for battery unavailability per demand is $10^{-3}$, with $90 \%$ imits set between $3 \times 10^{-4}$ and $3 \times 10^{-3}$. This estimate is based on the frequency of inspection and tests (e.g., the batteries are visually inspected daily, checked monthly for specific gravity and individual cell voltages, and tested yearly for load capability). 
Description of the Fault Trees

The fault trees contained in Appendix $C$ and $D$ we re selected from the complete trees used in the detailed analysis. The detailed fault trees went beyond the component level to determine if subtle dependencies existed among system elements. For example, detailed subtrees were drawn for the control circuits of breakers to determine whether any failures could cause breakers to trip inadvertently. Likewise, subsystems of the diesel generator system were analyzed to determine whether a single event could cause the loss of all diesels.

The reduced fault trees use the same basic structure as the detailed tree, except that the reduced fault trees include only events appearing in the single-and double-cut sets of the detailed fault tree. Triple-cut sets were considered; however, none were found to be significant.

The BWR reduced 'tree shown in Appendix $C$ represents a portion of channel $Z A$ of Division I. Similar trees were constructed for each of the other channels $(Z B, Z C, Z D)$; however, they are not included in this report. The PWR reduced tree shown in Appendix D represents a portion of Train A of the two-train system. Since the quantitative calculations show that the failure probabilities of Train A buses are nearly identical to those on the corresponding Train B buses, subtrees for Train $B$ buses were not developed.

The subtrees shown in Appendices $A$ and $B$ are of the same basic structure. Each subtree identifies single and double events causing insufficient power. The four events that cause insufficient power on an emergency bus can be described as follows:

1. Open circuit on bus, including all open circuits on the bus structure or the main feeder circuits that would deenergize the bus.

2. Short circuit on bus, including all short circuits on the bus structure or on the bus side of all circuit breakers connected to the bus. These shorts would cause the bus voltage to drop below an acceptable level.

3. Insufficient power input to bus, or the loss of power at the bus from external failures. Typically, such an event may be caused by a single event (e.g. , a short or an open circuit in the transmission line, transforme $r$ cable, or other bus that feeds the bus of concern) or by a double event (e. g. , the loss of offsite power to a $4160-V$ bus and a failure of the diesel generator).

4. Load short circuit and breaker fails to open, or a double event: a short on any feeder cable emanating from a bus and failure of the circuit breaker to open. The net result of this event is equivalent to that of a short circuit on the bus.

\section{Analysis Results}

The emergency power system was analyzed for insufficient power by determining unavailability and cumulative probability of failure for each of the emergency power buses. The calculated quantities are defined as follows: 
Unavailability, $q$ = probability that immediately following LOCA a state of insufficient power exists on the bus.

Cumulative Probability of Failure, $p(T)=$ probability that the first failure of the bus occurs by time $\mathrm{T}$.

In the model used in this study, $\mathrm{p}(\mathrm{T})=\lambda \mathrm{T}$, where $\lambda$ is the effective failure rate for the bus, and is assumed to be constant. Therefore, $\lambda$ rather than $p(T)$ is tabulated. The results of the analysis are listed in Appendix $E$ for the BWR and Appendix $F$ for the PWR.

The BWR event, "total loss of electric power," Q000, given success at LOCA, was computed for various times subsequent to LOCA. The results are given in Table 3 .

Table 3. Q000, given success at LOCA

\begin{tabular}{cccc}
\hline \multirow{2}{*}{$\begin{array}{c}\text { Time } \\
\text { after LOCA }\end{array}$} & Q med & Upper & Lo\% bounds \\
\hline $1 \mathrm{hr}$ & $<10^{-8}$ & - & - \\
$24 \mathrm{hr}$ & $4.0 \times 10^{-7}$ & $4.0 \times 10^{-6}$ & $4.0 \times 10^{-8}$ \\
$4 \mathrm{mo}$ & $6.0 \times 10^{-6}$ & $6.0 \times 10^{-5}$ & $6.0 \times 10^{-7}$ \\
$9 \mathrm{mo}$ & $7.5 \times 10^{-6}$ & $7.5 \times 10^{-5}$ & $7.5 \times 10^{-7}$ \\
\hline
\end{tabular}

For the PWR event, "insufficient power (IP) after LOCA, given success at LOCA," the computed quantity is the probability of failure with no repair with in the allowed outage time at time $T$. The probabilities of this event for various times after LOCA are given in Table 4.

Table 4. Probability of IP after LOCA, given successful start.

\begin{tabular}{ccll}
\hline $\begin{array}{c}\text { Time } \\
\text { after LOCA }\end{array}$ & $Q_{\text {med }}$ & Lower & Upper \\
\hline $1 \mathrm{hr}$ & $2.0 \times 10^{-7}$ & $2.0 \times 10^{-8}$ & $2.0 \times 10^{-6}$ \\
$24 \mathrm{hr}$ & $5.2 \times 10^{-6}$ & $5.2 \times 10^{-7}$ & $5.2 \times 10^{-5}$ \\
$4 \mathrm{mo}$ & $7.5 \times 10^{-5}$ & $7.5 \times 10^{-6}$ & $7.5 \times 10^{-4}$ \\
$9 \mathrm{mo}$ & $7.6 \times 10^{-5}$ & $7.6 \times 10^{-5}$ & $7.6 \times 10^{-4}$ \\
\hline
\end{tabular}

How these estimates were calculated is described in a subsequent discussion of the quantification method.

The emergency power system was evaluated for susceptibility to common-mode failures (e.g., loss of the emergency power system due to a single event). The evaluation accounted for single events such as calibration errors or drifts of relay settings, fire, electrical transients, and mechanical reactions caused by a LOCA that could incapacitate the emergency power system. However, because of equipment 
diversity and physical separation, no credible single event was found that would cause the loss of both offsite and onsite power sources.

In the BWR case, the probability of losing all four diesel generators at LOCA is estimated to be $10^{-3}$ for one specific event (i.e., the application of large ESF loads on all diesels shortly after LOCA). This compares with a failure probability of $10^{-6}$ for failing four diesels due to independent events.

In the PWR case, the probability of losing all onsite power (i.e., both diesel generators) at LOCA, if off site power is lost, is estimated to be $10^{-2}$ for a specific event, (i.e., the simultaneous application of all ESF loads at LOCA, a normal requirement for the plant analyzed). This compares with a failure probability of both diesel generators of $10^{-3}$ for independent events.

Several other common-mode events that pertain to the diesel generators were reviewed; however, based on engineering judgment, the probability of these events is at least one order of magnitude less than that of independent events. These events, the refore, were only treated qualitatively.

- The most stringent requirements of the emergency power system exist immediately after LOCA and persist for the next $24 \mathrm{hr}$. The common-mode failure evaluation of the offsite power system, therefore, was addressed to events that would occur coincident with or be caused by LOCA. Accordingly, the electrical system was reviewed to determine whether pipe whip, missiles, steam jets, or any other mechanical reaction associated with the pipe break would result in loss of offsite power. Because of the isolation and separation between the offsite power system and the primary coolant system, no mechanic al reaction associated with LOCA is a significant initiating event for loss of offsite power. While initiating events such as fire, tornadoes, and lightning may induce common-mode failures of the offsite power system, the probability of such noncausally related events occuring coincident with a LOCA is deemed to be much lower than the independent unavailability of the system.

The electrical reaction associated with a large, primary-coolant pipe break has a causal relation with the offsite power system, i.e., a LOCA results in a turbinegenerator trip which, in turn, challenges the transient stability of the transmission grid due to the sudden loss of generation. Using information provided by the Federal Power Commission, an assessment was made of the probability of losing offsite power due to a LOCA-induced power grid transient (turbine trip). This is estimated to be $10^{-3}$ for any locale in the United States and was the value used in the study.

The onsite dc system is well isolated from all LOCA-related events, and no causally related event was found that would incapacitate it at LOCA. The only causally related event found that could incapacitate the diesel generators at LOCA, provided that the offsitc power systcm is lost, is that of a potential overload. Each diesel generator must start large motors within $15 \mathrm{sec}$ after LOCA if offsite power is lost. The estimated inrush for such loads is about $10,000 \mathrm{kVA}$ for the BWR and 20,000 kVA. for the PWR. 'The probability of tripping the four BWR diesel generators under these conditions is estimated to be $10^{-3}$; it is $10^{-2}$ for the two PWR diesel generators. In. 
addition, all four diesels in the BWR have a common cooling water return line which, if blocked, could cause all four diesels to overheat and fail.. The probability of occurrence was determined to be very low for this chain of events.

Method of Quantification

As defined earlier, unavailability at LOCA includes the loss of the high-voltage (HV) switchyard (loss of offsite power) and failure of the diesel generators (loss of onsite power). The principal contributor for unavailability of offsite power at LOCA is loss of input from the net, $q(N E T)$. Since the technical specifications allow for extended plant operation with loss of part of the HV switchyard, the re is a contribution from any downtime on the HV buses and the transfer network; however, such contributions were fourd to be negligible compared to $q(N E T)$.

In contrast, the technical specifications severely restrict plant operation with loss of any ac emergency bus. Thus, the major contributors to unavailability of the ac system at LOCA are $\mathrm{q}(\mathrm{NET})$ and the probability that the diesel does not start, $q(E D G)$. Since all the emergency ac buses are fed from the $4160-V$ buses, unavailability at LOCA is the product of $q(N E T)$ and $q(E D G)$.

For the dc buses, unavailability at LOCA is represented by the coincident loss of offsite power and the station battery. The diesel generators are ineffective for this case because dc power is required to connect the diesel generators to the $4160-\mathrm{V}$ bus. Thus, for the dc buses, unavailability at LOCA is $q(N E T)$ multiplied by the probability that the station batteries fail, q(BATTERY).

The estimate of $q(N E T)$ is based on utility experience, which was used to estimate the likelihood of losing offsite power due to the turbine trip that follows a LOCA. The value of $\mathrm{q}(\mathrm{NET})$ was estimated to be $1 \times 10^{-3}$. The failure rate of the net, $\lambda(\mathrm{NET})$, was determincd to be $2 \times 10^{-5}$. The estimate of $q(E D G)$ is $4 \times 10^{-2}$ with $1 \times 10^{-3}$ for q(BATTERY).

\section{C.ONCLUSIONS}

Using quantitative techniques, we obtained the probability of failure values for the buses in question. It should be noted, however, that the accuracy of the available data plays an important role in determining these values. Confidence bounds were established to provide a realistic approach to risk assessment. It is also possible to determine the sensitivity of the top event to variations in system design or failure rates.

Our experience reenforces the following conclusions:

1. A multidisciplinary team is best able to perform an analysis on a complex system.

2. Contributions from at least two analysts are required to ensure a complcte and accurate tree.

3. Analysts working on different portions of a complex system should interface with each other. 


\section{REFERENCES}

1. Reactor Safety Study - An Assemssment of Accident Risks in U. S. Commerical Nuclear Power Plants, U. S. Atomic Energy Commission, Wáshington, D. C., Rept. WASH-1400 Draft (1974).

2. J. B. Fussell, "Fault Tree Analysis - Concepts and Techniques, "in Proc. Nato Advanced Study Institute on Generic Techniques of System Reliability Assessment, Live rpool, England, July 1973.

3. J. B. Fussell et al, "Fault Trees - A State of the Art Discussion, "IEEE Trans. Reliability R-23 (1), $51-55$ (1974).

4. D. F. Haasl, "Advanced Concepts in Fault Tree Analysis," in Proc. System Safety Symp., Seattle, 1965.

5. H. E. Lambert, Systems Safety Analysis and Fault Tree Analysis, Lawrence Livermore Laboratory, Rept. UCID-16238 (1973).

6. H. E. Lambert, Fault Tree Analysis: An Overview, Lawrence Livermore Laboratory, Rept. UCRL-75904 (1974).

7. Safety System Analytical Technology, Boeing Curnpany, Seattle, Rept. D2-113072-2 (1965). 


\section{APPENDIX A}

\section{BWR SYSTEM DESCRIPTION}

The major components of the BWR electrical power system are shown in Figs. $A-1$ and $A-2$. Offsite power sources and emergency power system interfaces for Units 2 and 3 of the BWR facility are shown in Figs. A-3 and A-4. 


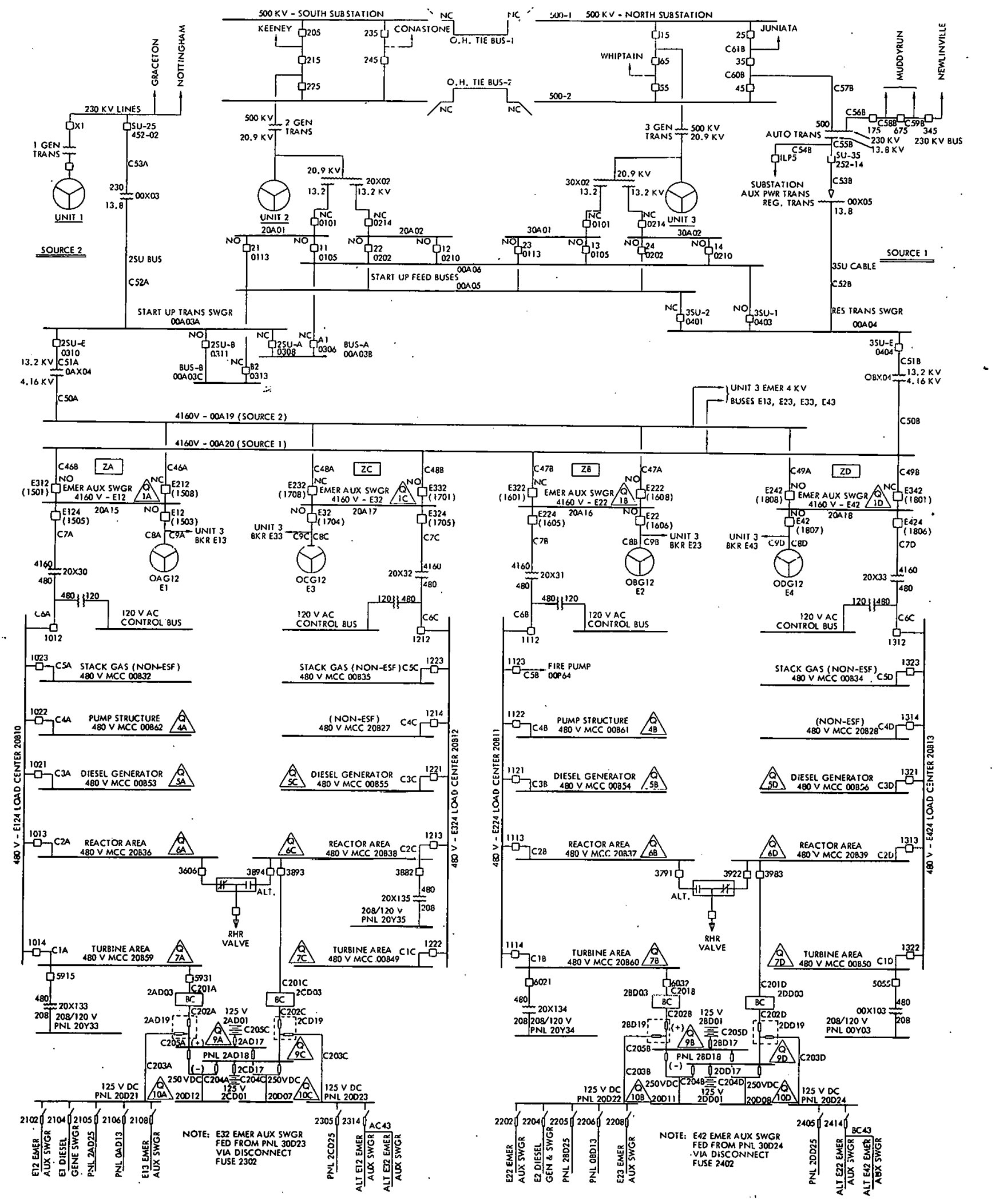

Fig. A-1. BWR single line diagram. 


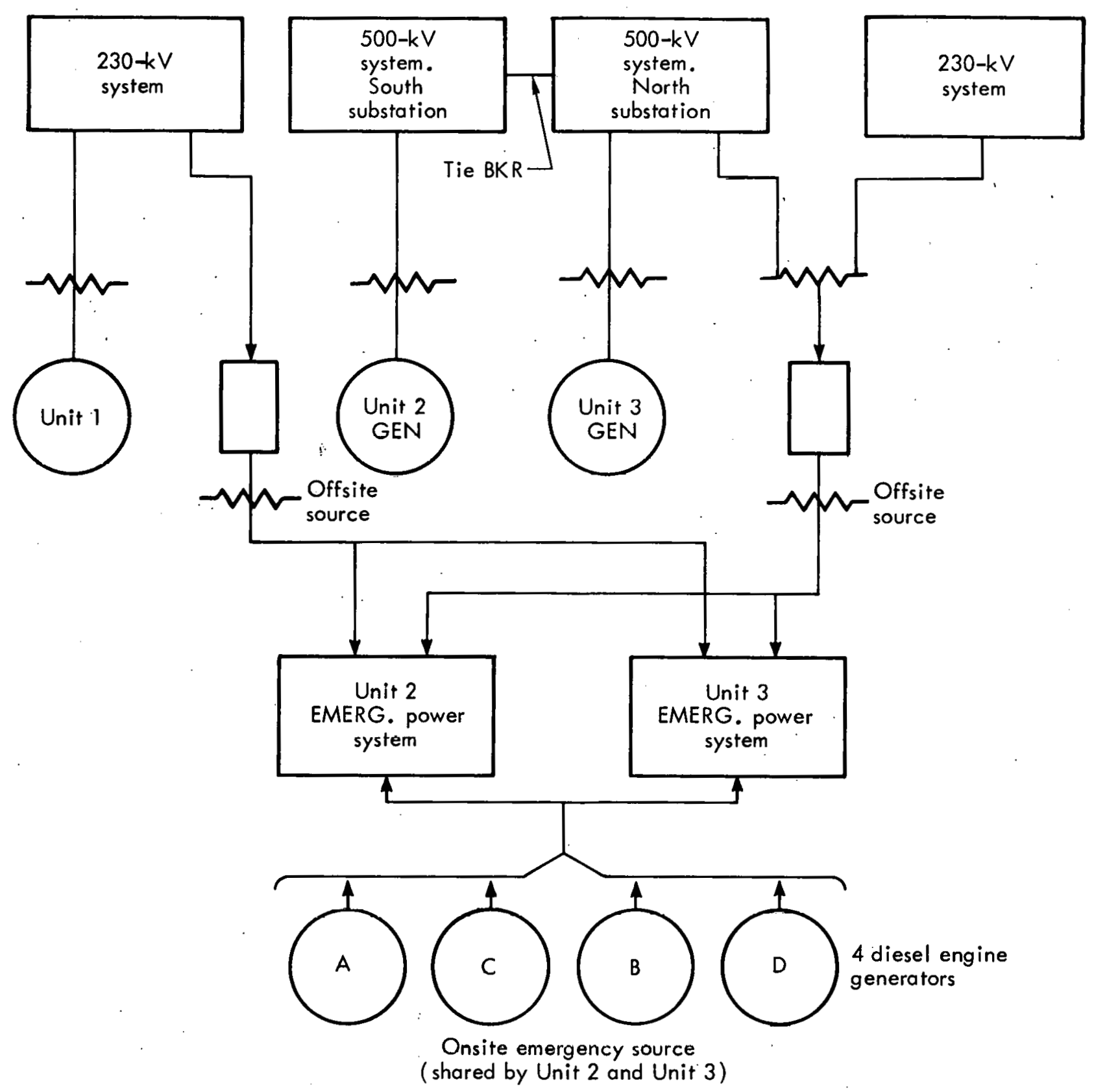

Fig. A-2. BWR simplified emergency-power block diagram. 


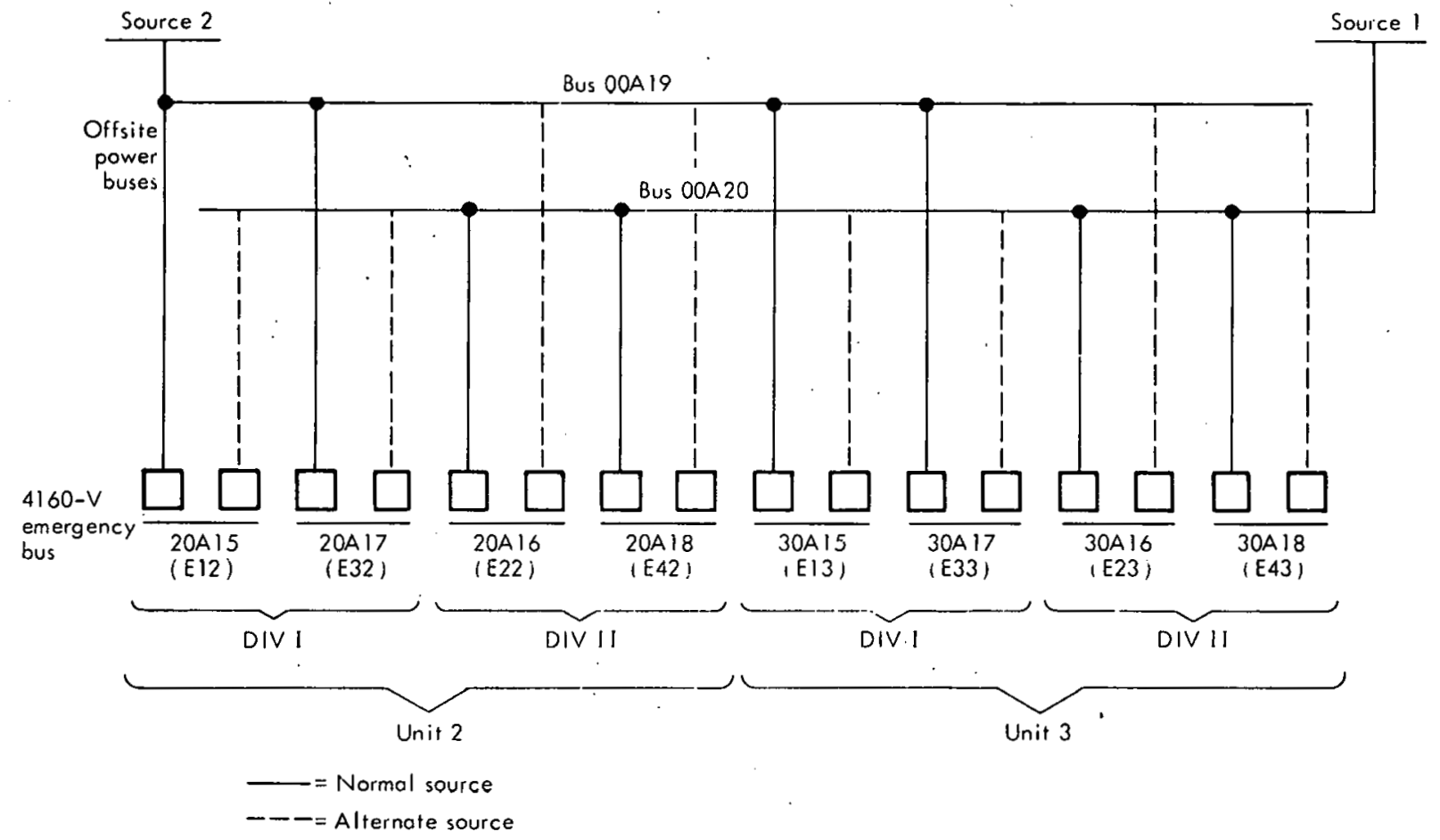

Fig. A-3. BWR 4160-V offsite power sources. 


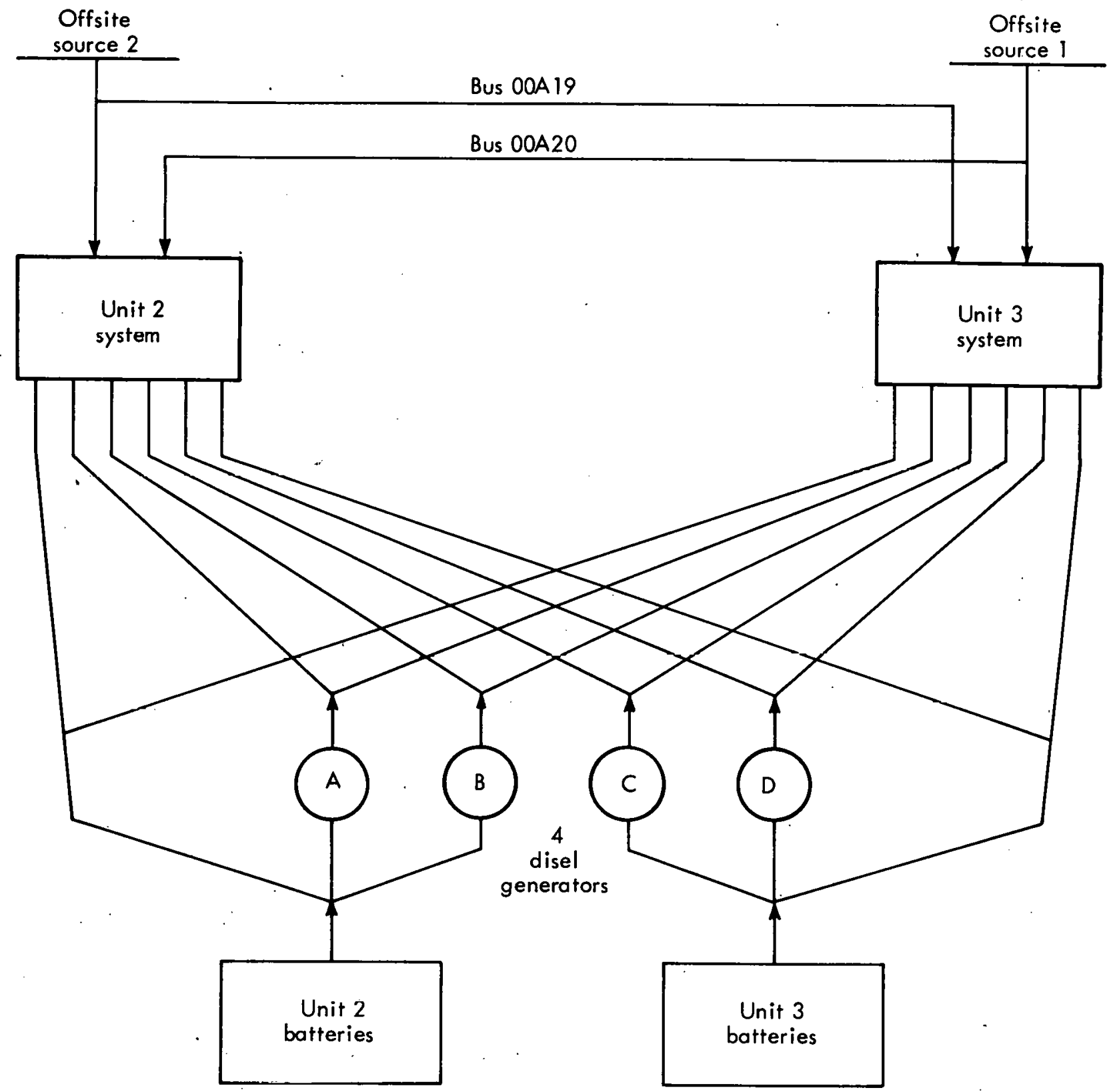

Fig. A-4. BWR Unit 2-Unit 3 emergency-power system interface. 
APPENDIX B

PWR SYSTEM DESCRIPTION

The major components of the PWR electrical power system are shown in Figs.

$\mathrm{B}-1$ and $\mathrm{B}-2$. 


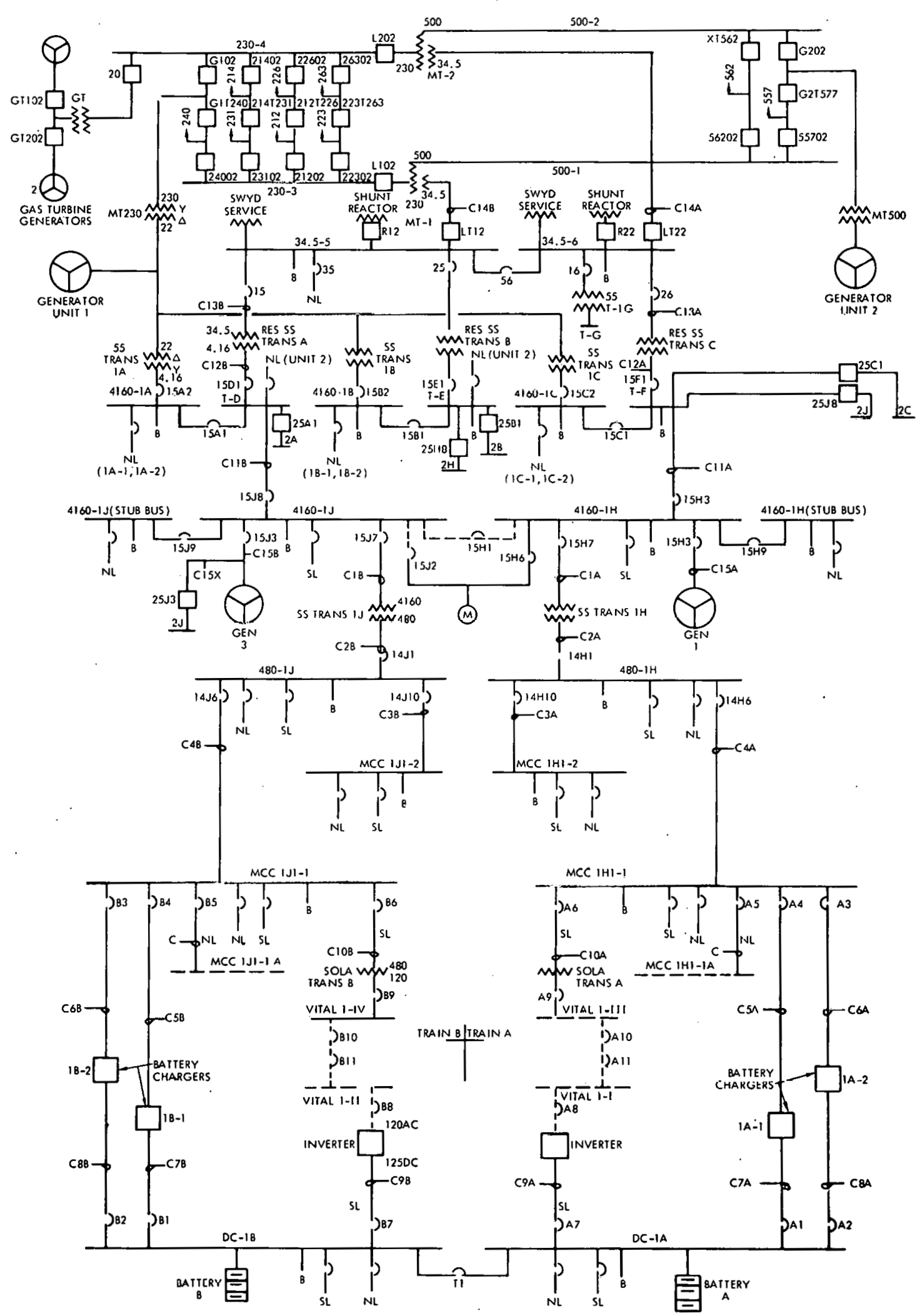

Fig. B-1. PWR single line diagram. 
Train B

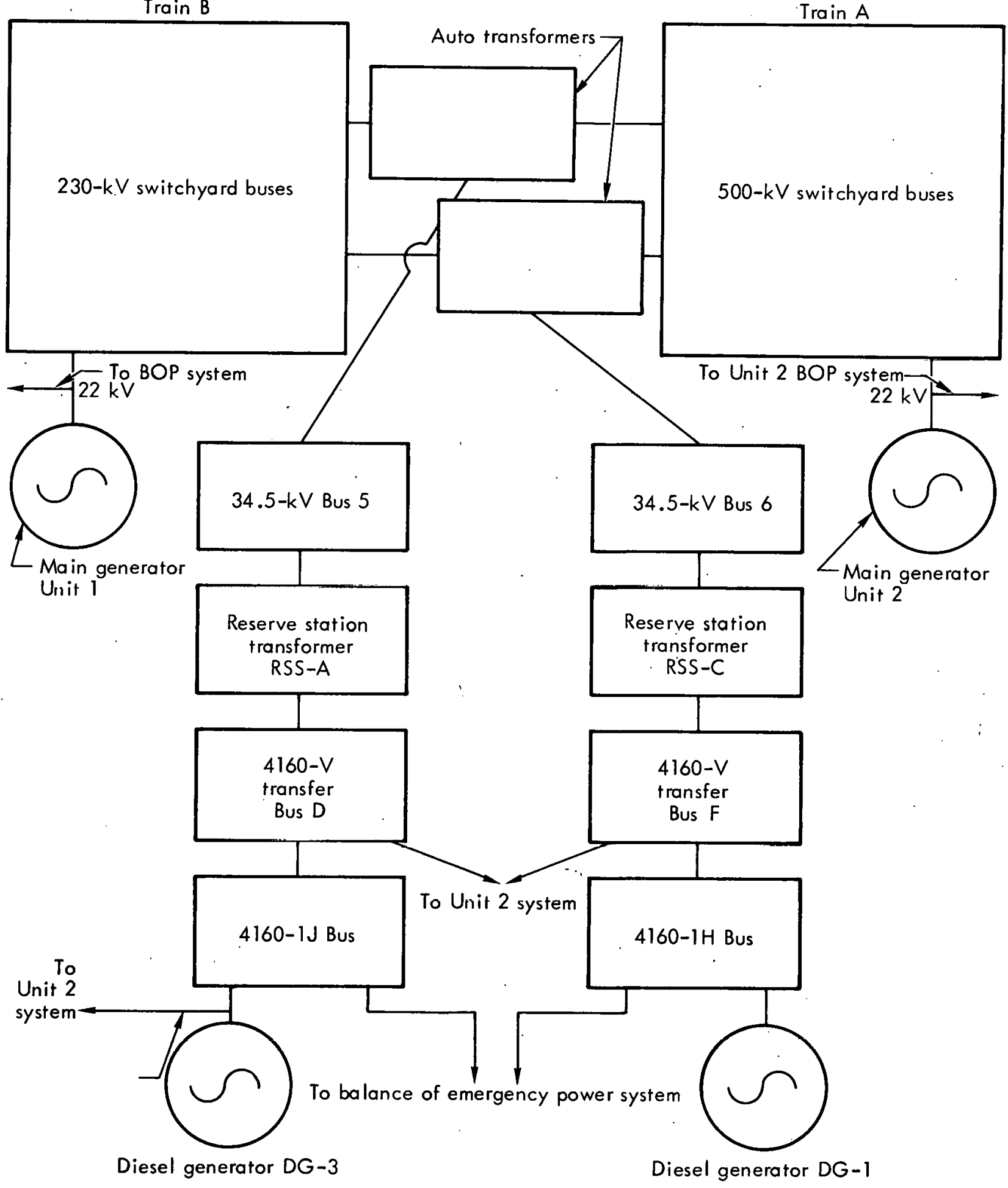

Fig. B-2. PWR simplified emergency-power block diagram. 


\section{APPENDIX C}

\section{BWR FAULT TREES}

This appendix contains the fault trees (Fig. C-1) used to analyze component failures for a portion of channel $\mathrm{ZA}$ in the BWR power bus schematic (see Appendix $A$, Fig. A-1). An explanation of the component failure notation is given in Table $\mathrm{C}-1$.

Table C-1. Key to BWR component failure notation.

SPACE No. 1 System identification

Examples $-Q=$ Electrical power distribution system

$\mathrm{T}=$ Diesel oil system

$\mathrm{X}=$ Diesel gene rator system

SPACE No. 2, 3: Component type

Examples- BS = Bus

$\mathrm{BY}=$ Battery

$C A=$ Cable (conductor)

$\mathrm{CB}=$ Circuit breake $\mathrm{r}$

$F U=$ Fuse

$\mathrm{TR}=$ Power transformer

$\mathrm{GS}=$ Generator

$\mathrm{LA}=$ Lightning arrester

$\mathrm{GE}=$ Generator

$\mathrm{DL}=$ Diesel

$\mathrm{PP}=$ Pipe

$\mathrm{KV}=$ Solenoid-operated valve

MS = Motor starter

PS = Pressure switch

$\mathrm{RC}=$ Relay

$\mathrm{LT}=$ Light

$O T=$ Potential transformer

WR $=$ Wire

$\mathrm{OO}=$ Noncomponent event

$\mathrm{PM}=\mathrm{Pump}$

SPACE No 4: Failure mode

Examples-S = Short (on buses, conductors, etc.)

$Q=$ Short circuit (on imput contact or when side is not specified)

$\mathrm{V}$ - Short circuit (output contact)

$\mathrm{B}=$ Open circuit

$\mathrm{K}=$ Fails to close

$\mathrm{H}=$ Overload

$\mathrm{F}=$ Loss of function

$\mathrm{X}=$ Operational fault

$P=$ Plugged

$R=$ Rupture

$\mathrm{Y}=$ Maintenance fault

$C=$ Closed

$\mathrm{O}=$ Open

$\mathrm{G}=$ Disengage

SPACE No. 5-8: Component number. A four-character designator for the specific component.

SPACE No. 9: Detection scheme

Example - $A=$ Annunciated indication

$\mathrm{R}=$ Remote monitoring

$\mathrm{Y}=$ Periodic test $(<1$ year inte rval)

$Z=$ Periodic test $(>1$ year interval) 
Table $C^{-1}$ (continued).

SPACE No. 10: Event type

$\begin{aligned} \text { Examples }-X & =\text { Circle } \\ Z & =\text { Diamond }\end{aligned}$

Example: QBSSOE42R/X = Circle that states short on Bus F 42 and is remotely monitored. 


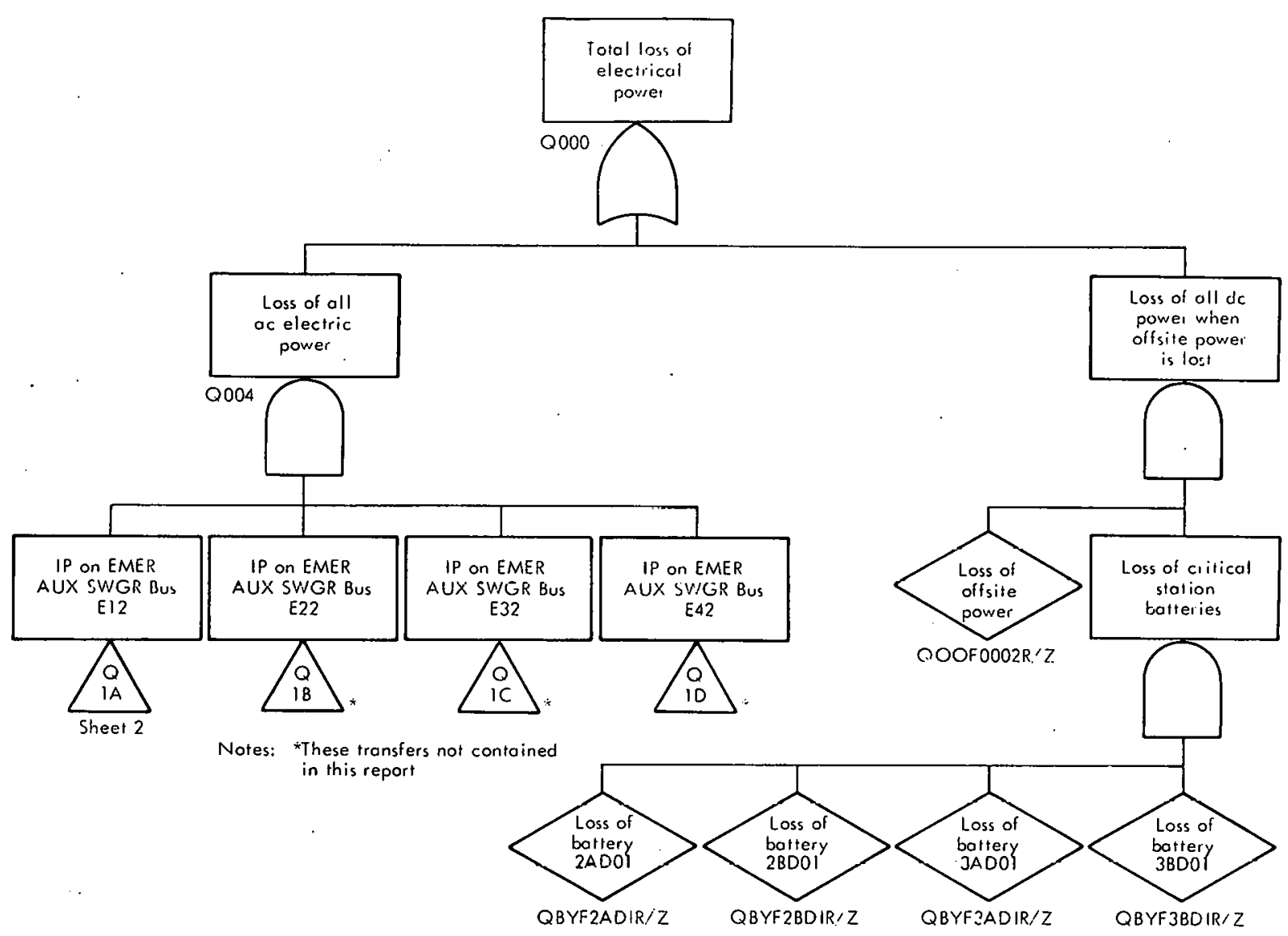

Fig. C-1. Fault tree for total loss of electric power (sheet 1). 


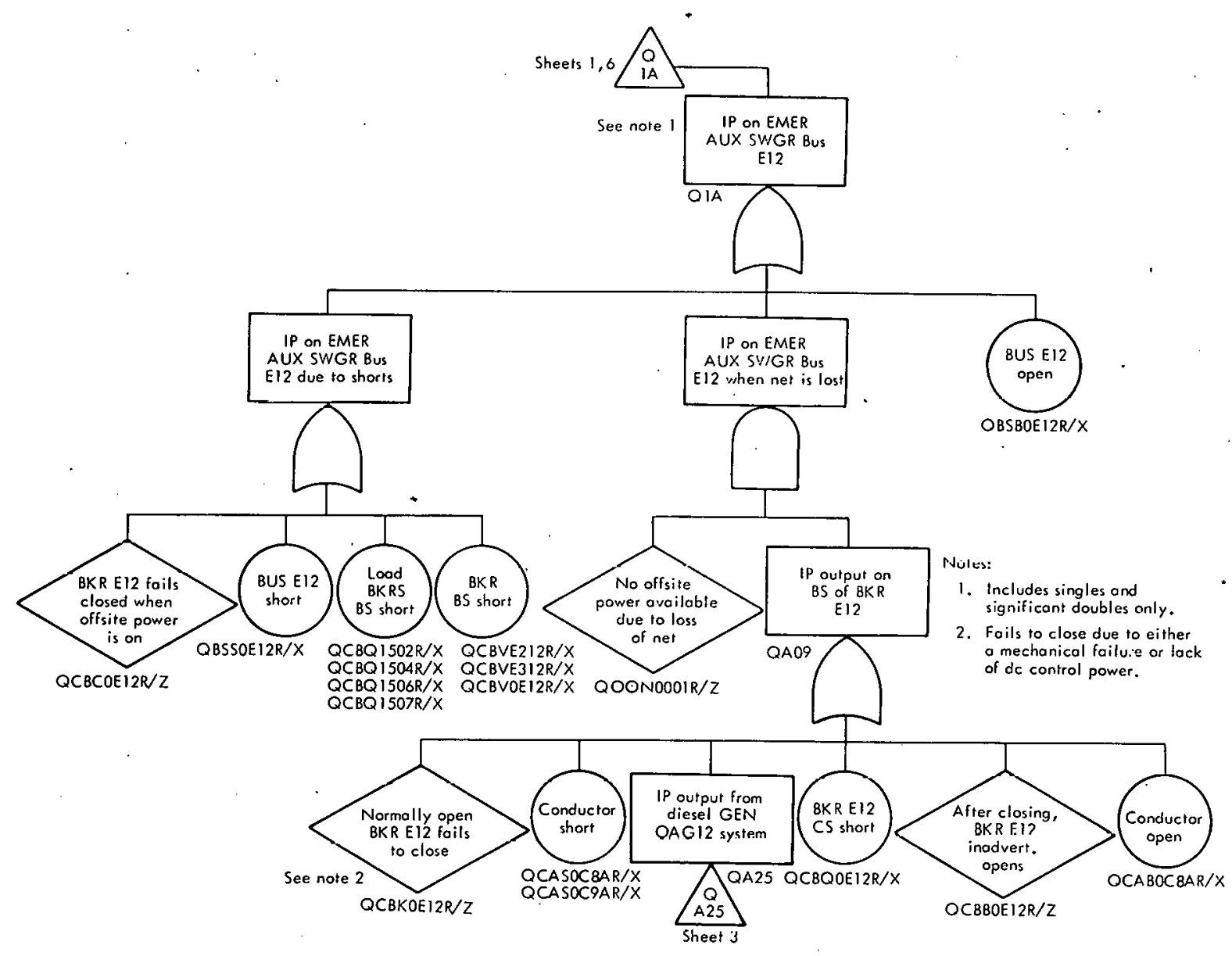

Fig. C-1. Fault tree for total loss of electric power (sheet 2). 


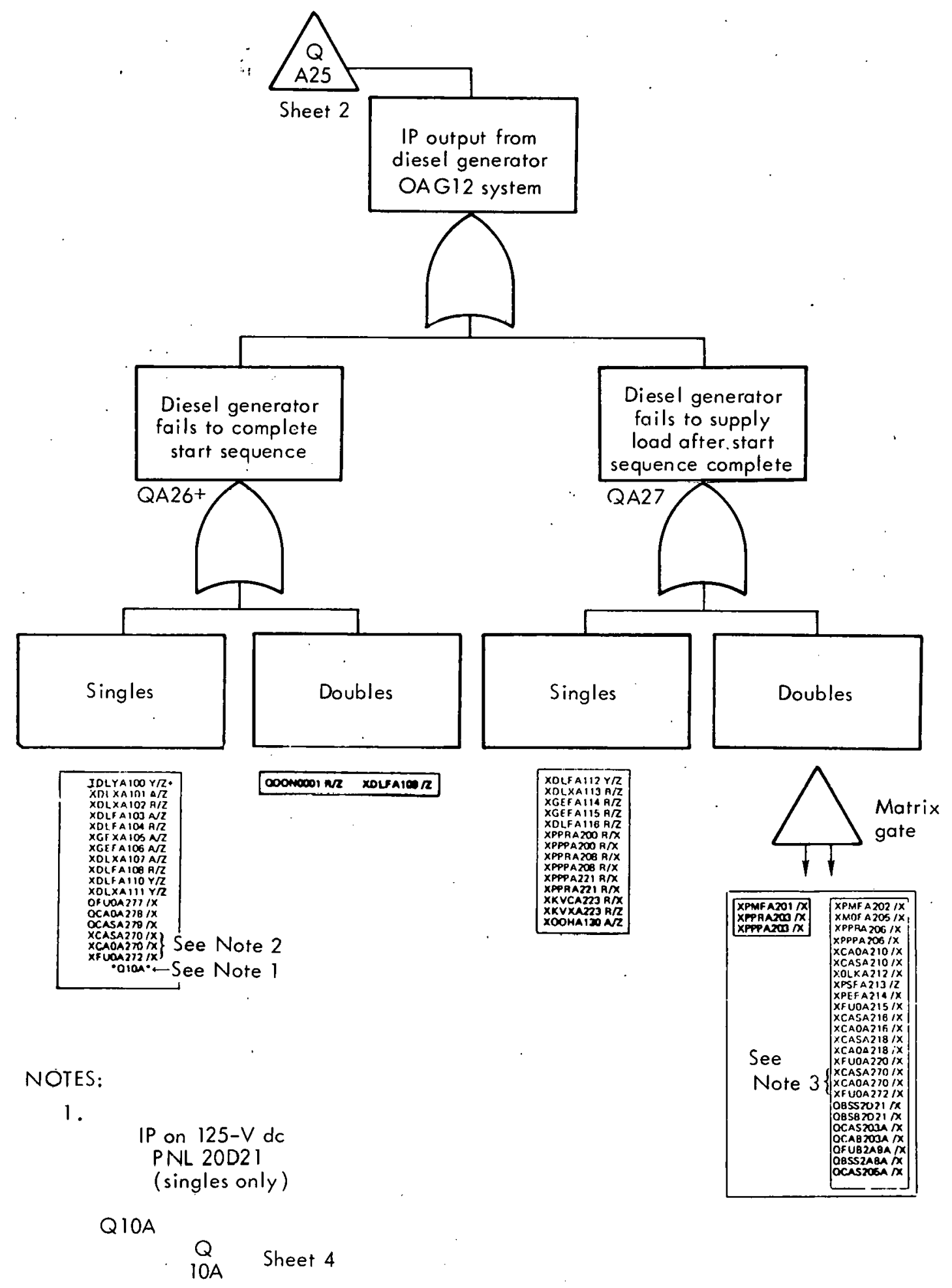

2. Unavailability during start sequence

3. Failure probability after start sequence complete

Fig. C-1. Fault tree for total loss of electric power (sheet 3 ). 


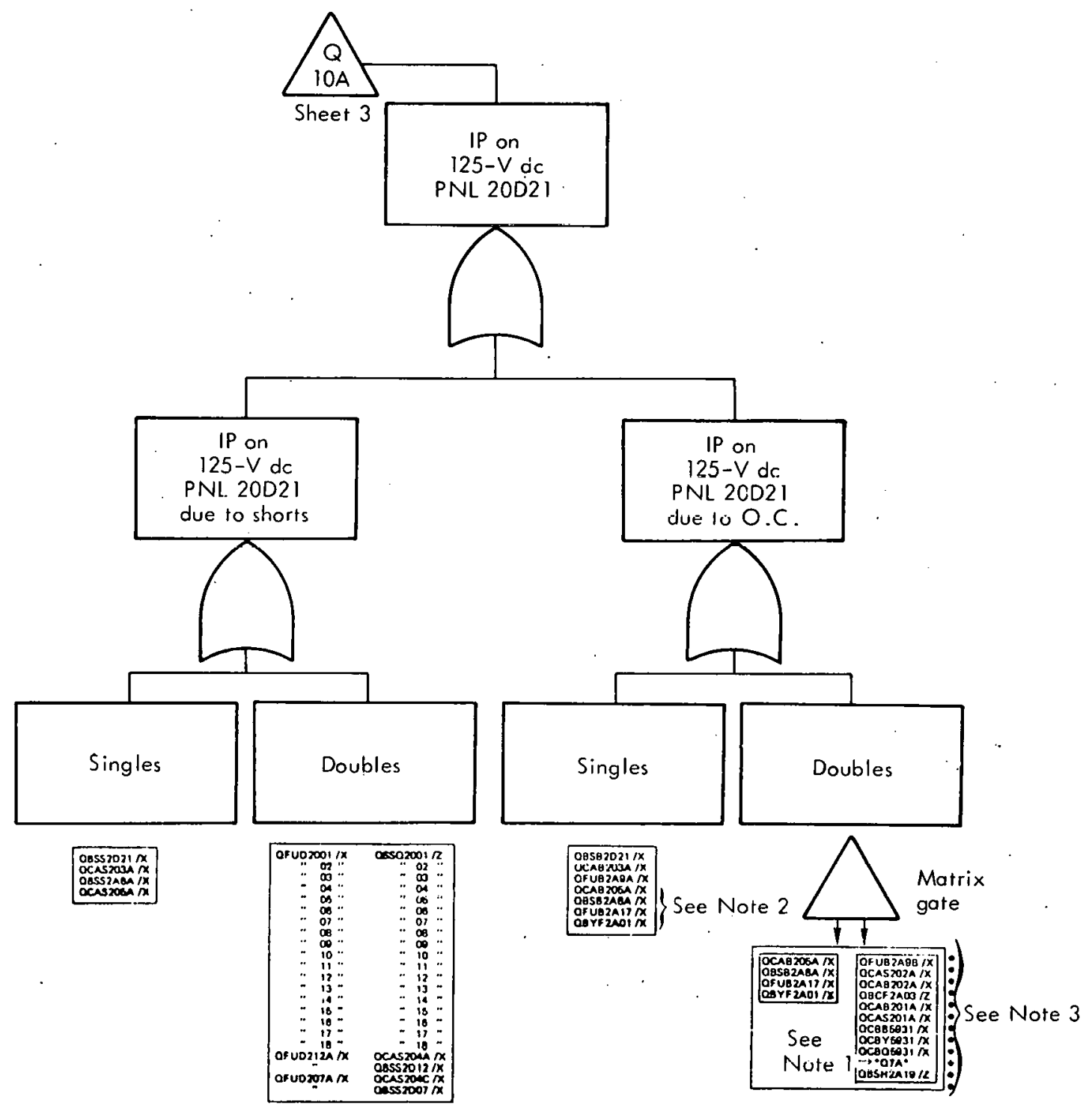

NOTES:

1. IP on turbine area MCC $20 B 50$ bus (singles only)

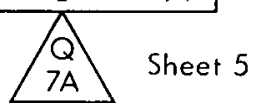

Note: Singles only

2. Valid as singles for less than 10 min after LOCA only.

3. Power output from PNL 2AD19 not required first $10 \mathrm{~min}$.

Fig. C-1. Fault tree for total loss of electric power (sheet 4). 


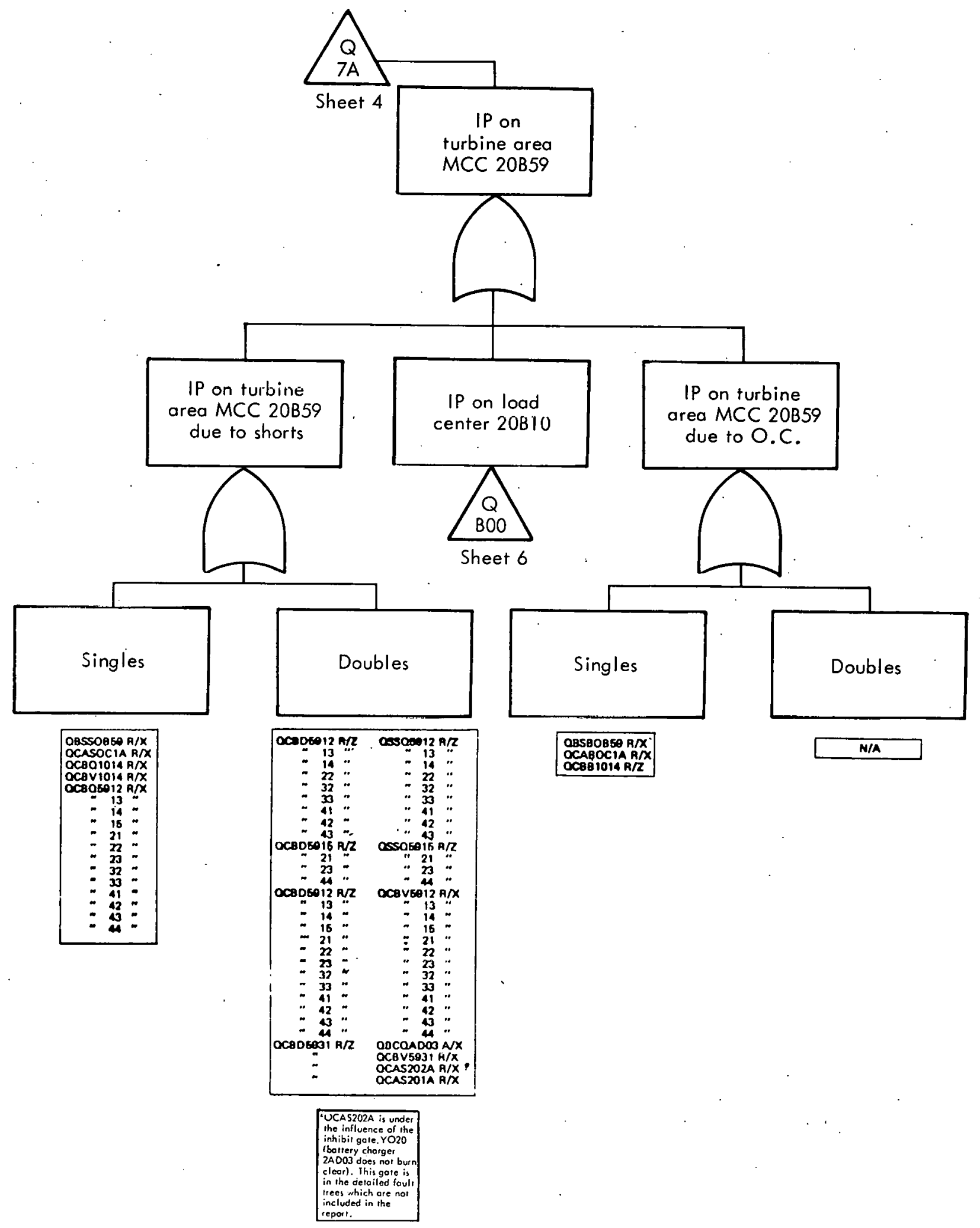

Fig. C-1. Fault tree for total loss of electric power (sheet 5). 


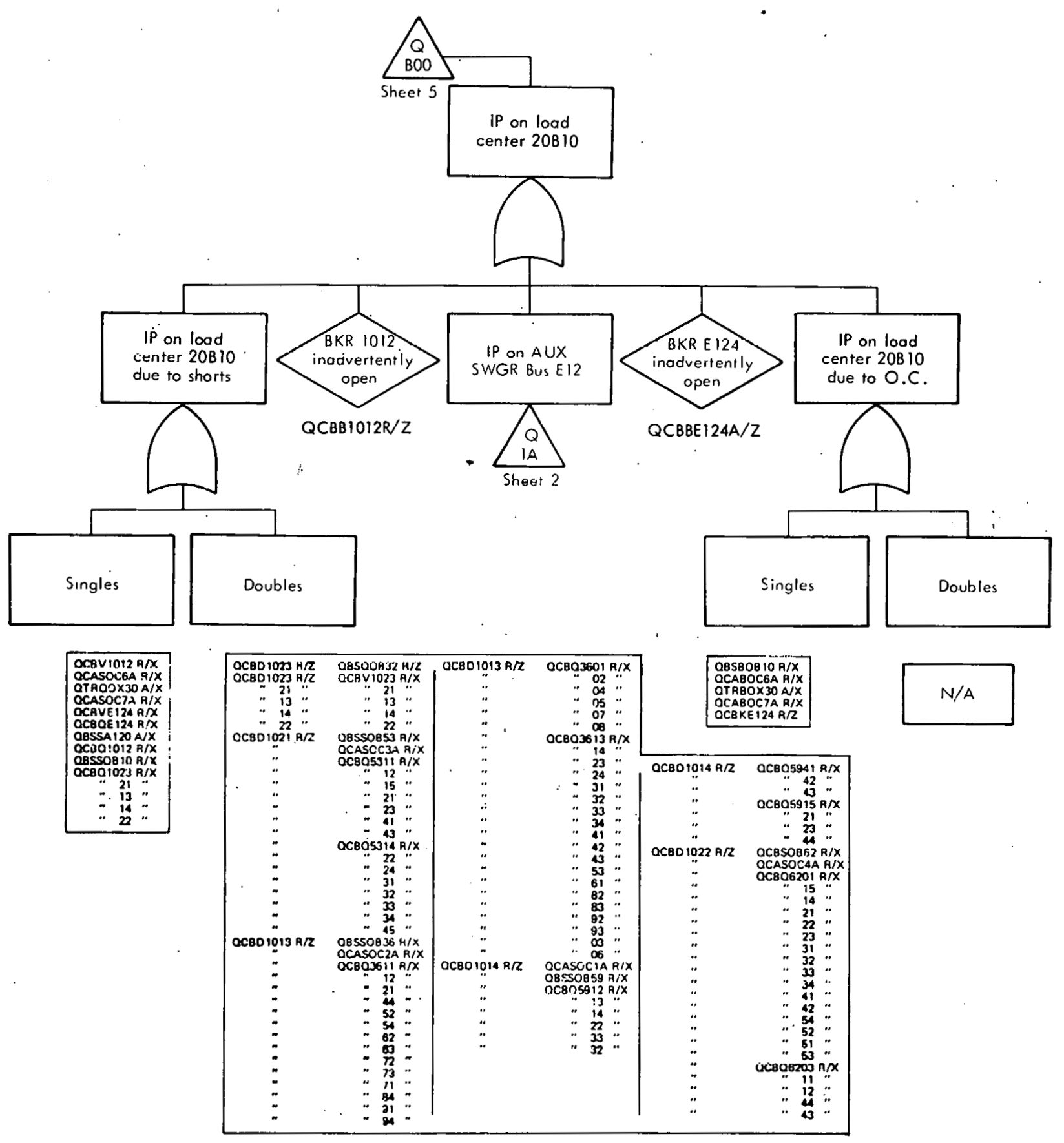

Fig. C-1. Fault tree for total loss of electric power (sheet 6). 


\section{APPENDIX D}

\section{PWR FAULT TREES}

This appendix contains the fault trees (Fig. D-1) used to analyze component failures for a portion of Train A in the PWR single line diagram (see Appendix $B$, Fig. B-1). An explanation of the component failure notation is given in Table D-1.

Table D-1. Key to PWR component failure notation.

SPACE Nn. 1: System identification

Examples $-Q=$ Electrical power distribution system

$T=$ Diesel oil system

$\mathrm{X}=$ Diesel generator system

SPACES No. 2, 3: Component type

Examples - BS = Bus

$\mathrm{BY}=$ Battery

$C A=$ Cable (conductor)

$\mathrm{CB}=$ Circuit breaker

$F U=$ Fuse

$\mathrm{TR}=$ Power transformer

$\mathrm{GS}=$ Grounding switch

$\mathrm{LA}=$ Lightning arrester

$\mathrm{GE}=$ Generator

$\mathrm{DL}=$ Diesel

$\mathrm{PF}=$ Pipe

$\mathrm{KV}=$ Solenoid-operated valve

SPACES No. 3-7: Component number. A four-character designator for the specific component.

Examples -E 312 Represents breaker No. E312

C46B Represents conductor No. C46B

SPACE No. 8: Failure mode

Examples $-S=$ Short (on buses, conductors, etc.)

$Q=$ Short circuit (on input contact or when side is not specified)

$\mathrm{V}=$ Short circuit (output contact)

$B=$ Open circuit

$\mathrm{K}=$ Fails to close

$\mathrm{H}=$ Overload

$F=$ Loss of function

$\mathrm{X}=$ Ope rational fault

$P=$ Plugged

R $=$ Rupture

$\mathrm{Y}=$ Maintenance fault

$\mathrm{C}=$ Closed

Examples: QBSOE42S = Short on Bus E42

QCB1322V = Short circuit on output contact of circuit breaker No. 1322 


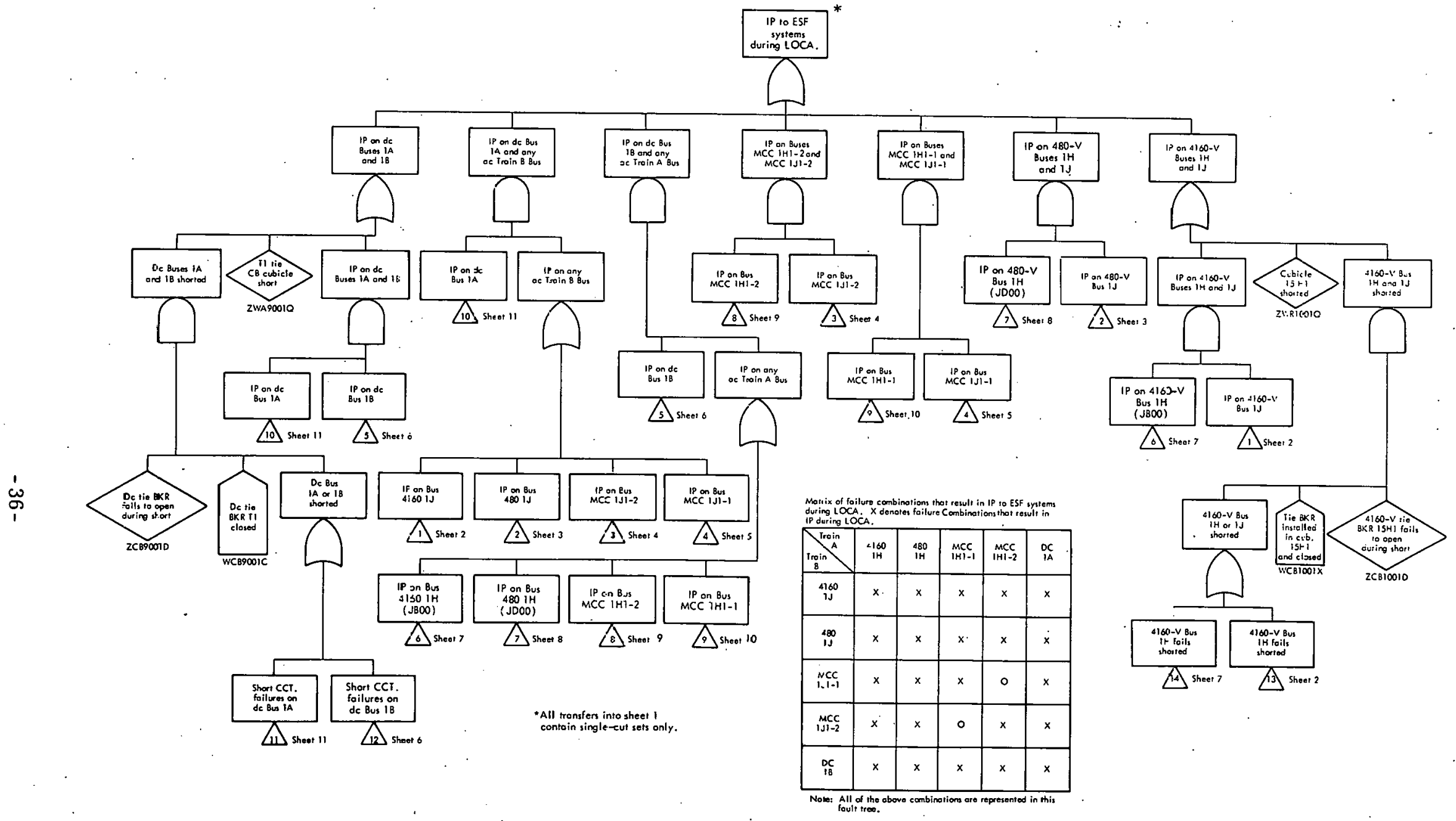

Fig. D-1. Fault tree for PWR emergency power system (sheet 1). 


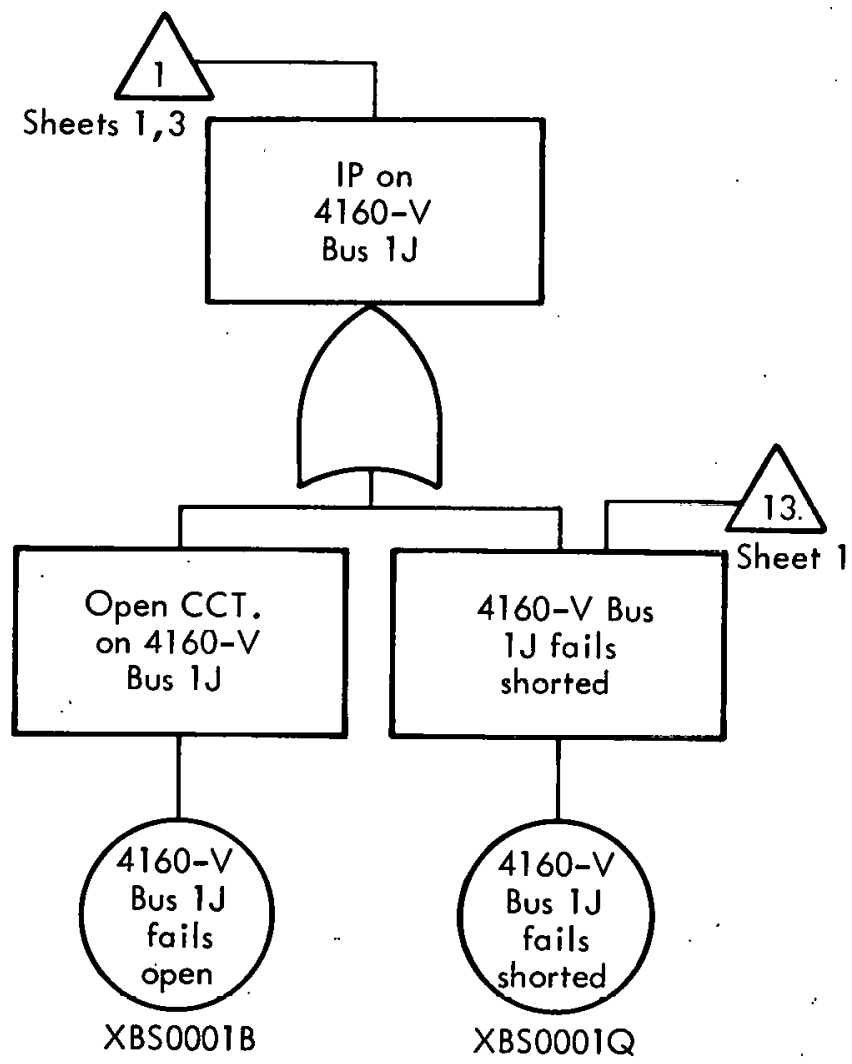

Fig. D-1. Fault tree for PWR emergency power system (sheet 2). 


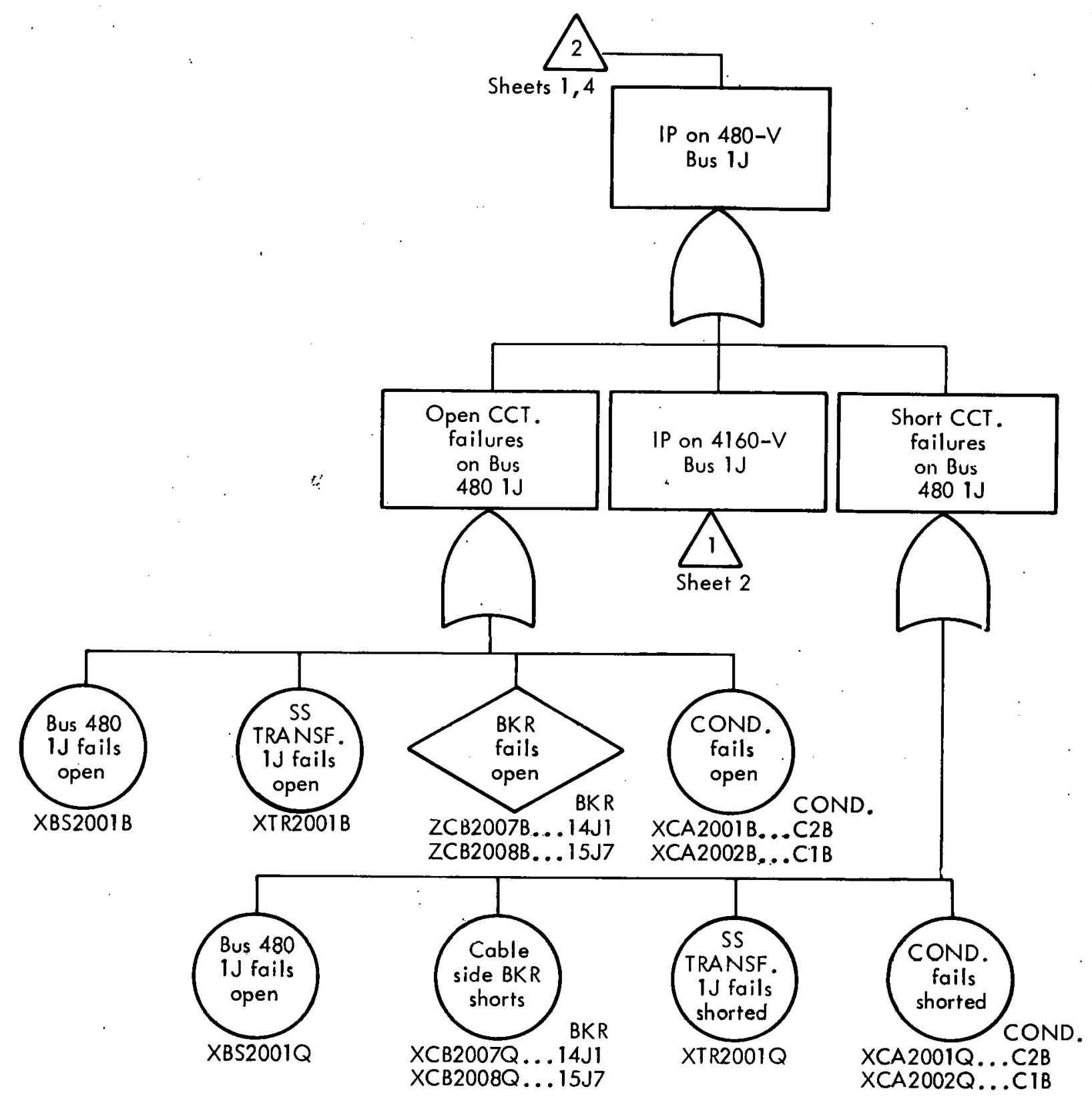

Fig. D-1. Fault tree for PWR emergency power system (sheet 3 ). 


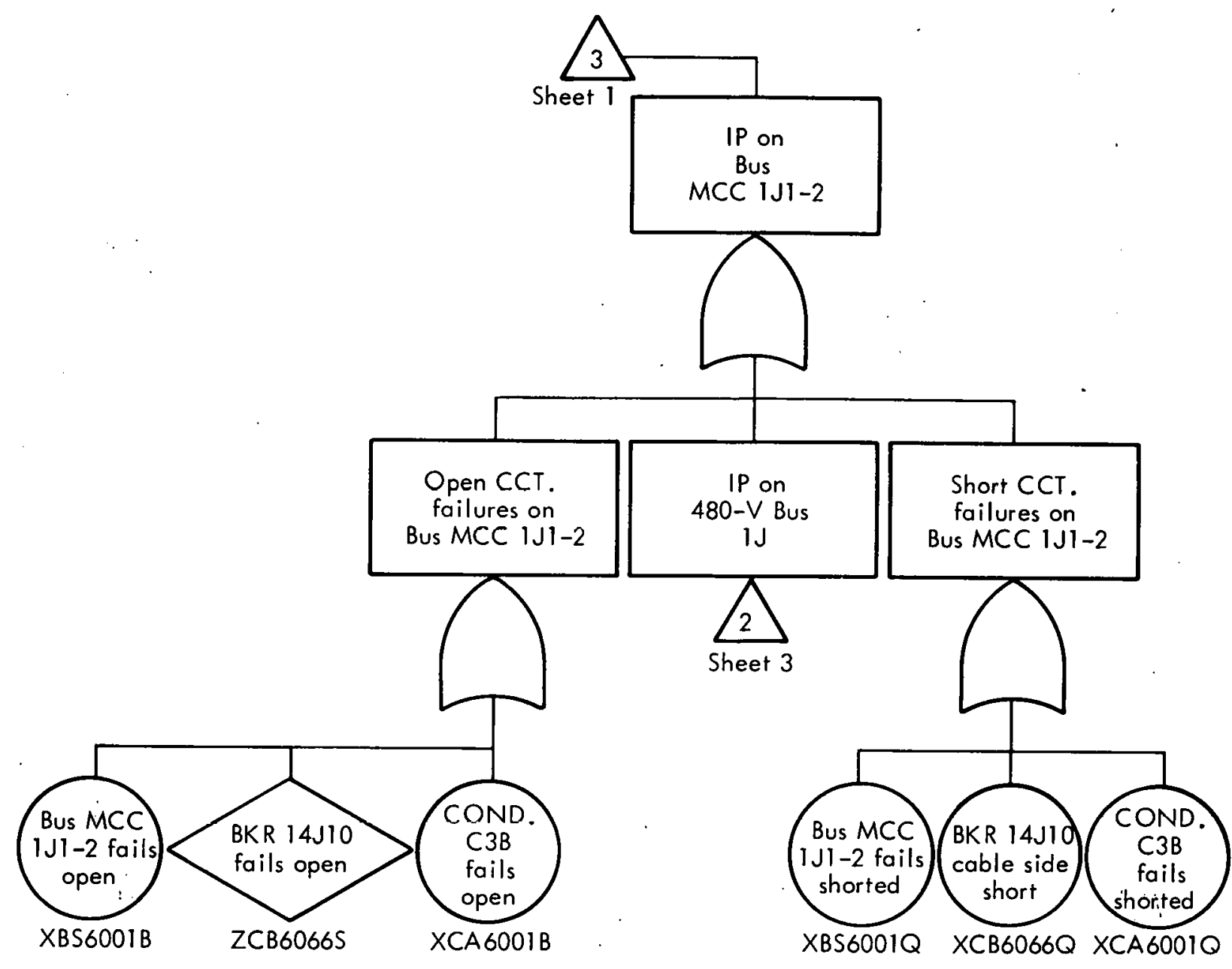

Fig. D-1. Fault tree for PWR emergency power system (sheet 4). 


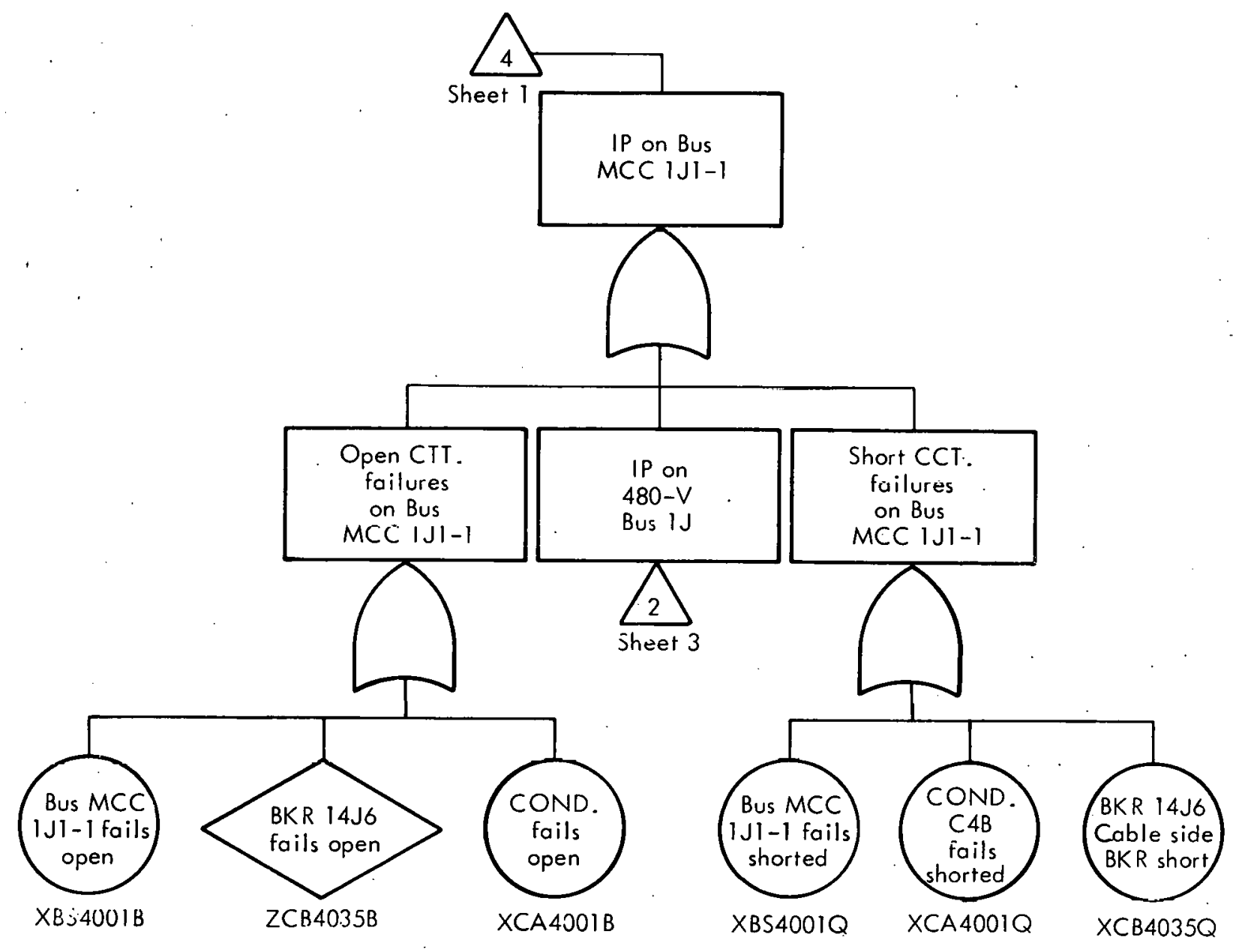

Fig. D-1. Fault tree for PWR emergency power system (sheet 5). 


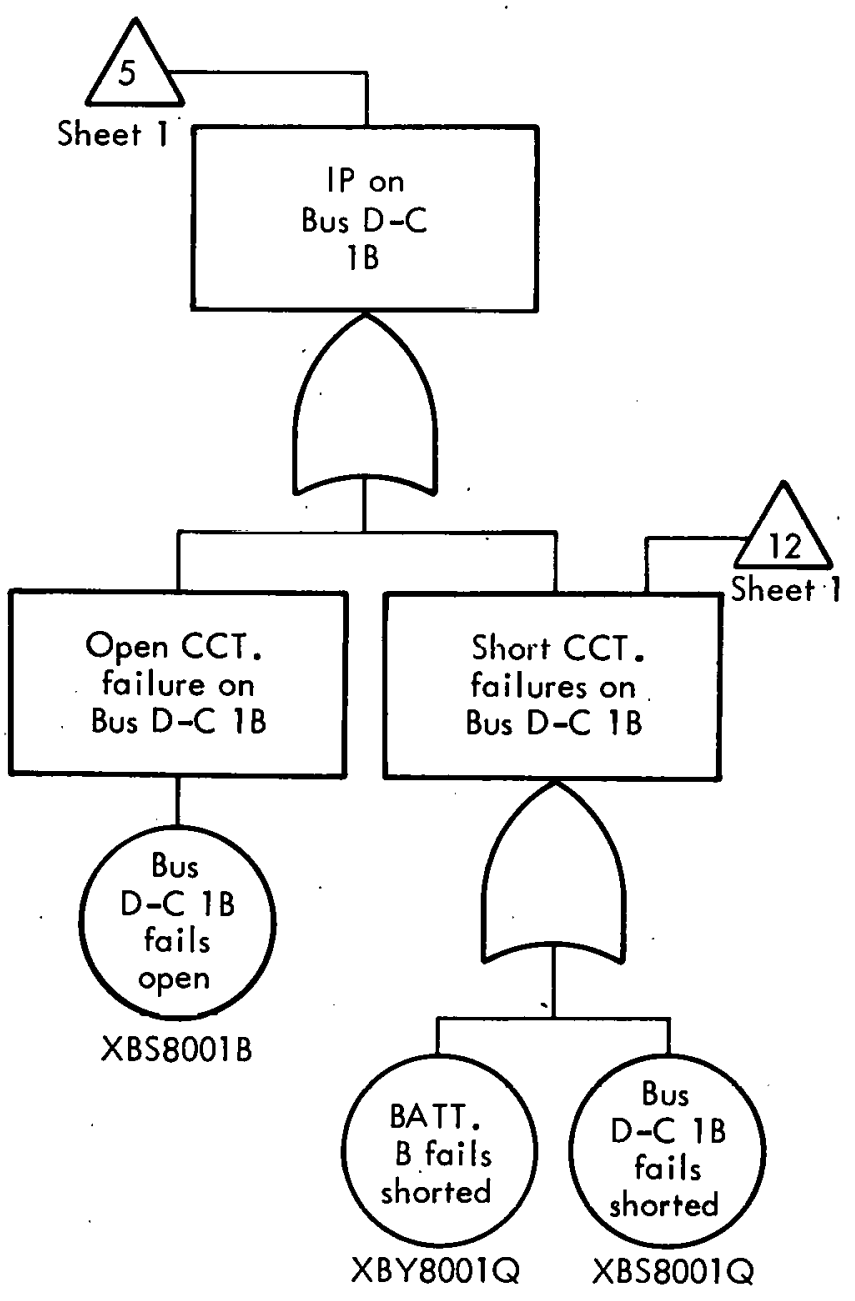

Fig. D-1. Fault tree for PWR emergency power system (sheet 6). 


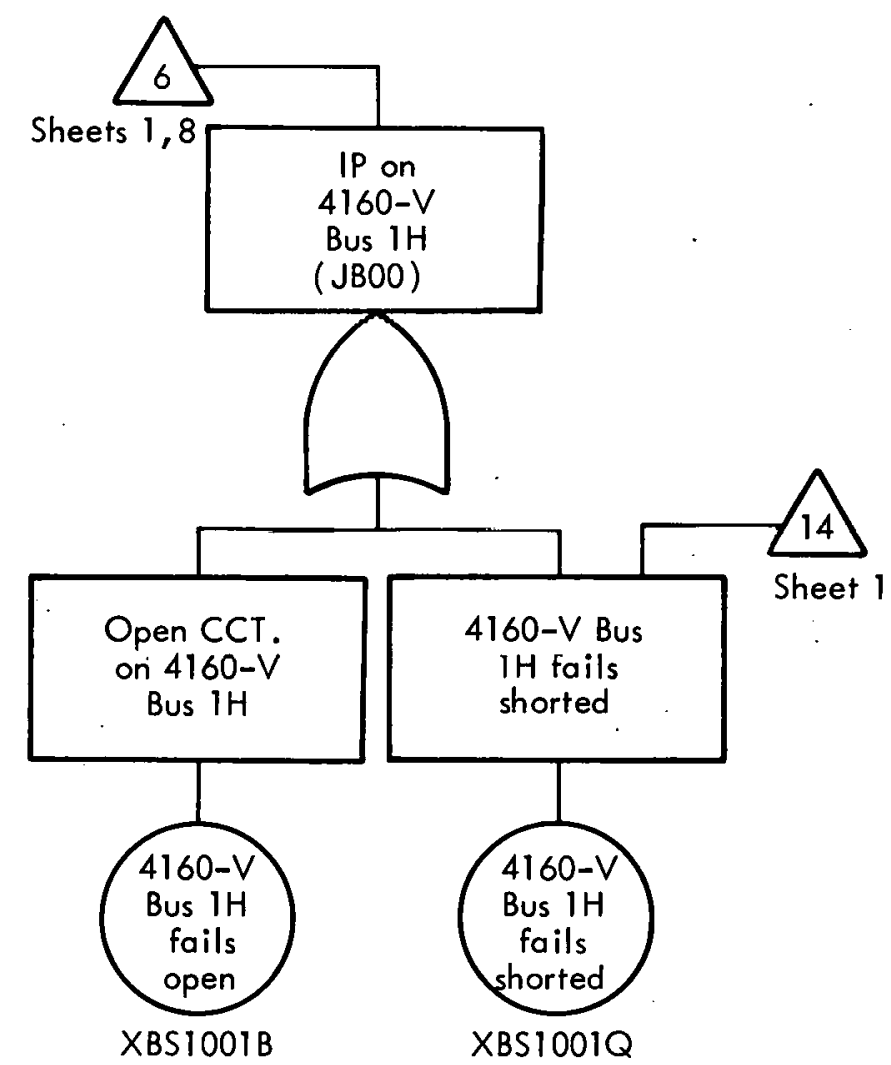

Fig. D-1. Fault tree for PWR emergency power system (sheet 7 ). 


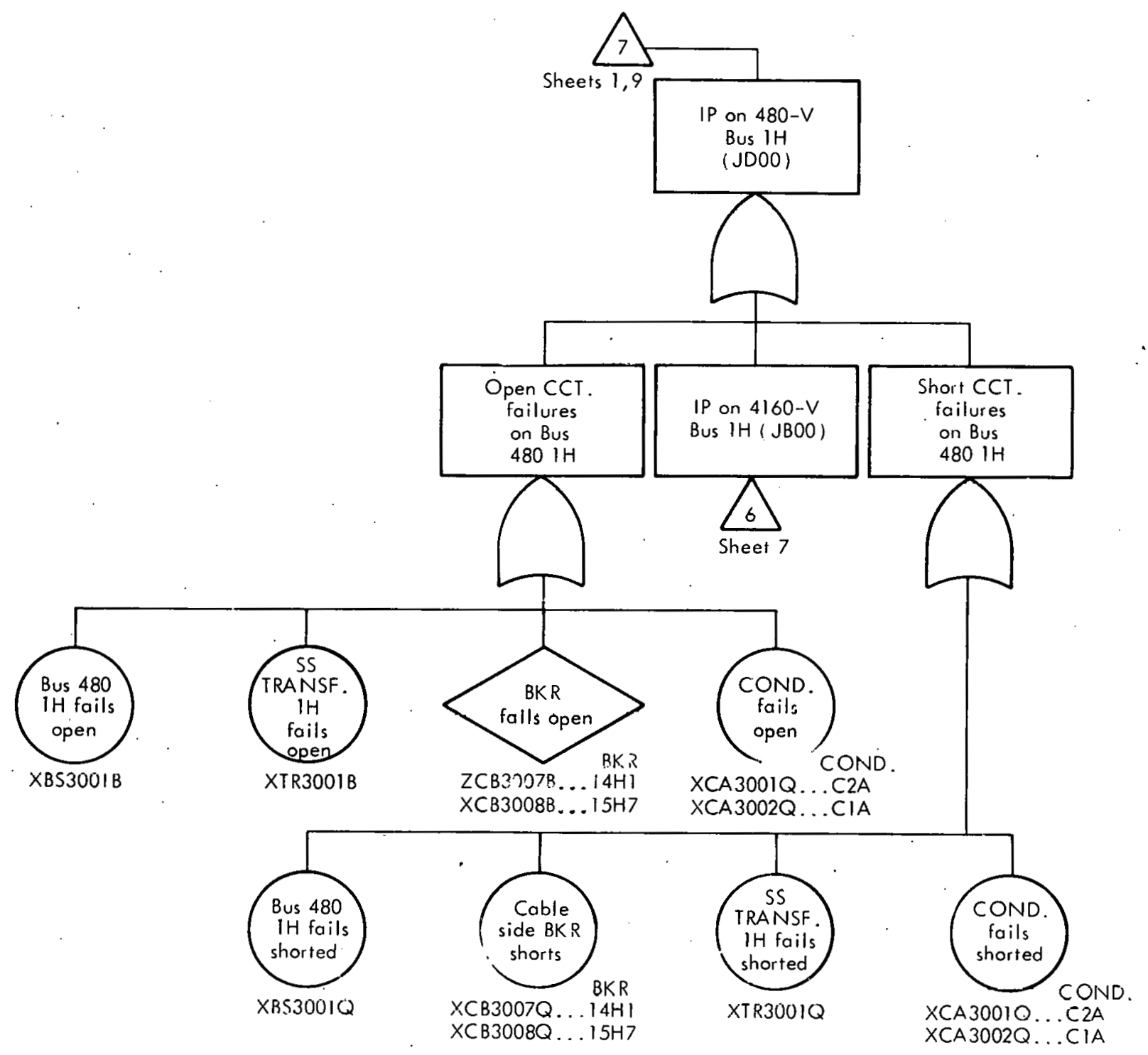

Fig. D-1. Fault tree for PWR emergency power system (sheet 8). 


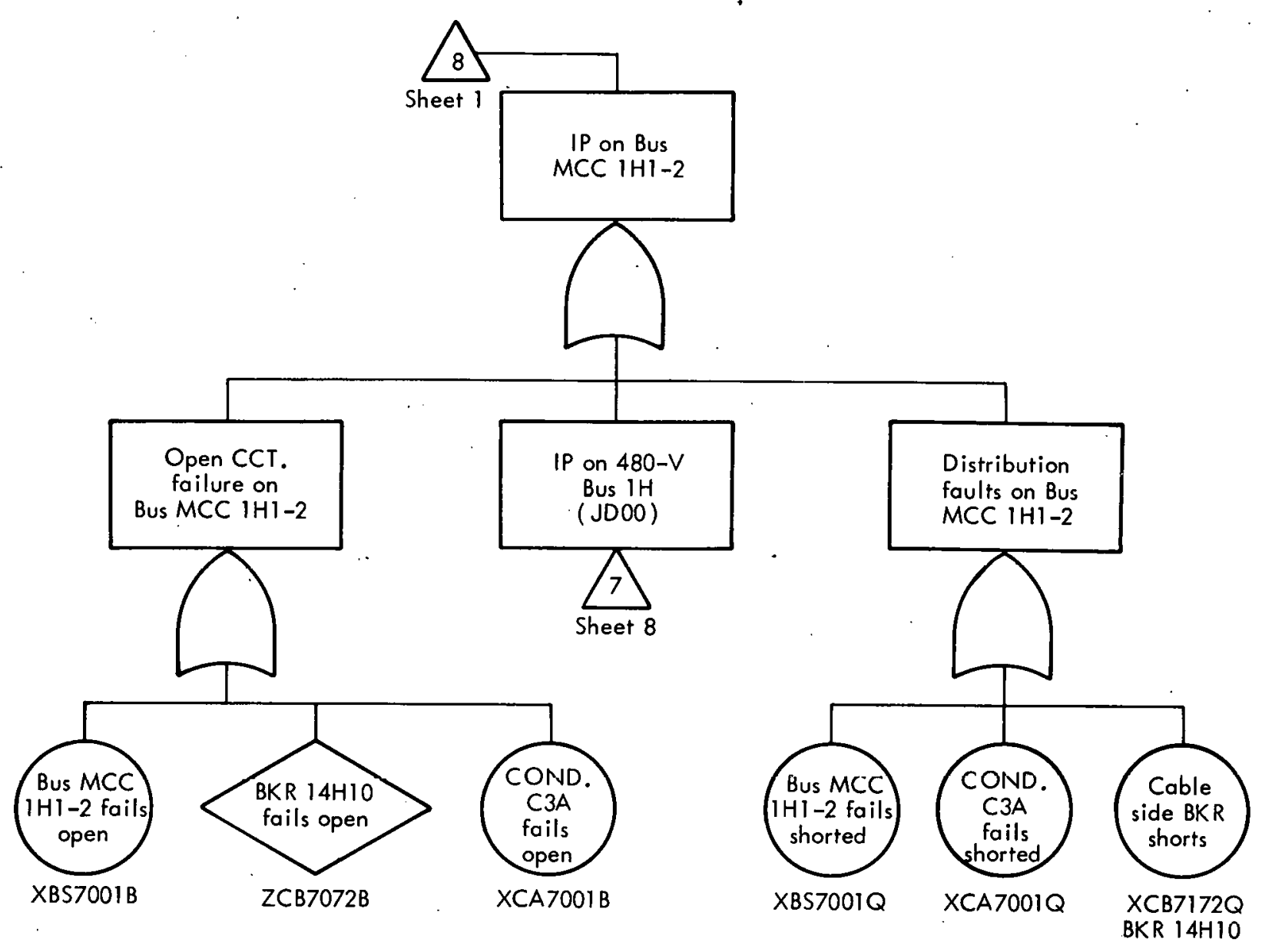

Fig. D-1. Fault tree for PWR emergency power system (sheet 9). 


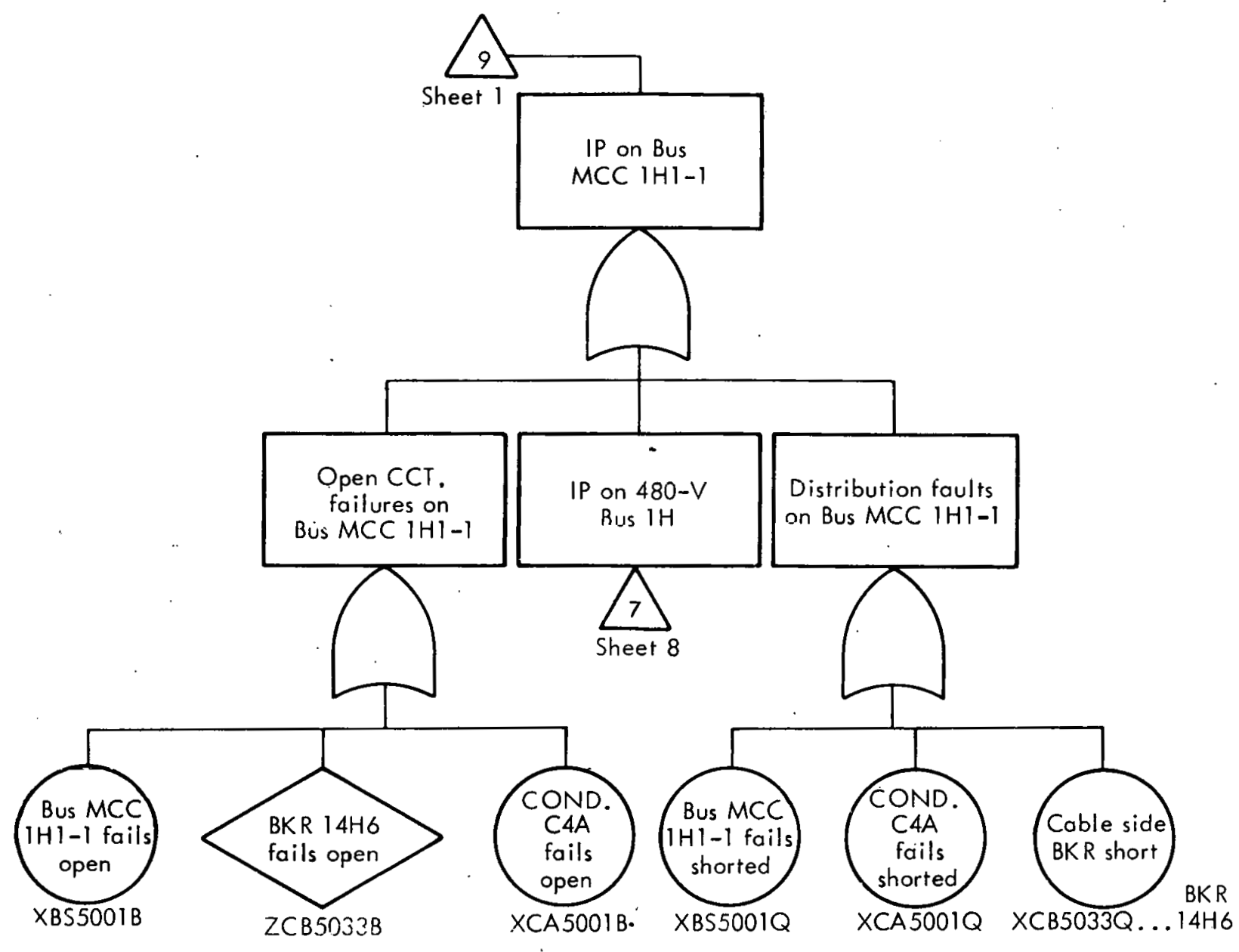

Fig. D-1. Fault tree for PWR emergency power system (sheet 10 ). 


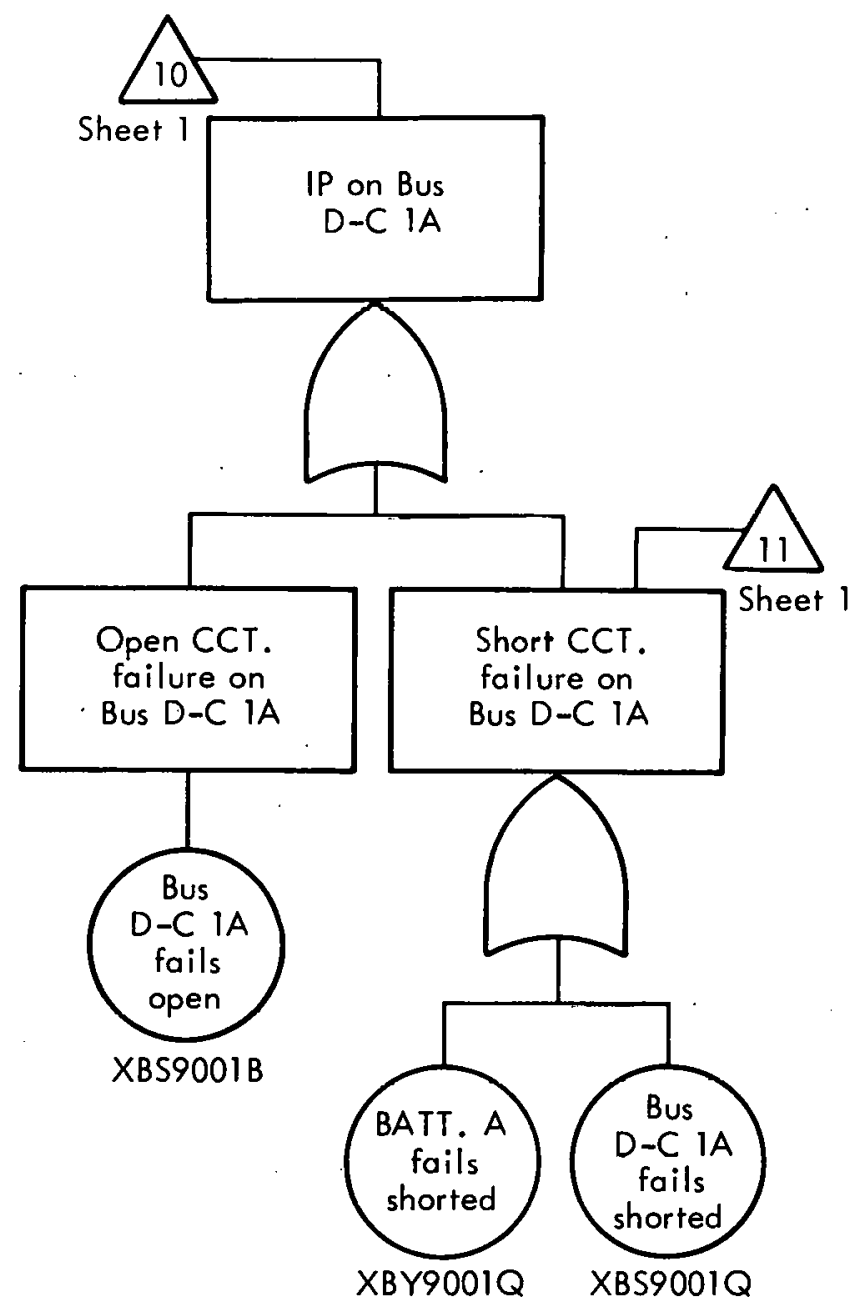

Fig. D-1. Fault tree for PWR emergency power system (sheet 11). 


\section{APPENDIX E}

BWR RESULTS

The BWR emergency power system was analyzed for insufficient power (IP). Representative quantitative results are given in Tables $\mathrm{E}-1$ and $\mathrm{E}-2$.

Table $E-1$. Unavailability $(q)$ and effective failure rates $(\lambda)$ for the emergency powe $r$ buses of a BWR.

\begin{tabular}{|c|c|c|c|c|c|c|}
\hline \multirow{2}{*}{$\begin{array}{l}\text { Fault tree } \\
\text { cvent }\end{array}$} & \multirow{2}{*}{$\underset{\text { Median }}{\mathrm{q}}$} & \multicolumn{2}{|c|}{$90 \%$ bounds } & \multirow{2}{*}{$\begin{array}{c}\lambda \\
\text { Median }\end{array}$} & \multicolumn{2}{|c|}{$90 \%$ bounds } \\
\hline & & Lower & Upper & & Lower & Upper \\
\hline $\mathrm{Q} 1 \mathrm{~A}^{\mathrm{a}}$ & $4 \times 10^{-5}$ & $4 \times 10^{-6}$ & $4 \times 10^{-4}$ & $3.1 \times 10^{-6}$ & $3.1 \times 10^{-7}$ & $3.1 \times 10^{-5}$ \\
\hline QB00 & $4 \times 10^{-5}$ & $4 \times 10^{-6}$ & $4 \times 10^{-4}$ & $1.2 \times 10^{-5}$ & $1.2 \times 10^{-6}$ & $1.2 \times 10^{-4}$ \\
\hline Q4A & $4 \times 10^{-5}$ & $4 \times 10^{-6}$ & $4 \times 10^{-4}$ & $1.5 \times 10^{-5}$ & $1.5 \times 10^{-6}$ & $1.5 \times 10^{-4}$ \\
\hline Q5A & $4 \times 10^{-5}$ & $4 \times 10^{-6}$ & $4 \times 10^{-4}$ & $1.5 \times 10^{-5}$ & $1.5 \times 10^{-6}$ & $1.5 \times 10^{-4}$ \\
\hline Q6A & $4 \times 10^{-5}$ & $4 \times 10^{-6}$ & $4 \times 10^{-4}$ & $1.5 \times 10^{-5}$ & $1.5 \times 10^{-6}$ & $1.5 \times 10^{-4}$ \\
\hline Q7A & $4 \times 10^{-5}$ & $4 \times 10^{-6}$ & $4 \times 10^{-4}$ & $1.5 \times 10^{-5}$ & $1.5 \times 10^{-6}$ & $1.5 \times 10^{-4}$ \\
\hline Q9A & $1 \times 10^{-4}$ & $1 \times 10^{-5}$ & $1 \times 10^{-3}$ & $6.3 \times 10^{-6}$ & $6.3 \times 10^{-7}$ & $6.3 \times 10^{-5}$ \\
\hline Q10A & $1 \times 10^{-4}$ & $1 \times 10^{-5}$ & $1 \times 10^{-3}$ & $7.5 \times 10^{-6}$ & $7.5 \times 10^{-7}$ & $7.5 \times 10^{-5}$ \\
\hline Q11A & $1 \times 10^{-4}$ & $1 \times 10^{-5}$ & $1 \times 10^{-3}$ & $1.5 \times 10^{-5}$ & $1.5 \times 10^{-6}$ & $1.5 \times 10^{-4}$ \\
\hline Q000 & $1 \times 10^{-6}$ & $1 \times 10^{-7}$ & $1 \times 10^{-5}$ & & & \\
\hline Q004 & $1 \times 10^{-6}$ & $1 \times 10^{-7}$ & $1 \times 10^{-5}$ & & & \\
\hline
\end{tabular}

\footnotetext{
${ }^{a}$ See schematic (Appendix A, Fig. A-1) for event descriptions.
} 
Table E-2. Quantitative results for fault tree analysis on channel ZA.

1) Q1A: IP on $4160-\mathrm{V}$ BUS E12

Unavailability at LOCA

Failure rate.

$$
\begin{aligned}
& Q=4 \times 10^{-5} \\
& \lambda=3.1 \times 10^{-6}
\end{aligned}
$$

MAJOR C.ONTRIBUTORS

Loss of NET and diesel fails to start

Loss of NET and diesel fails to start or stops

$$
\begin{aligned}
& \mathrm{Q}=4 \times 10^{-5} \\
& \lambda=3.1 \times 10^{-6}
\end{aligned}
$$

DETAILED ANALYSIS: $Q=q(N F T) \cdot q(E D G)$

Loss of NET

Diesel fails to start

Breaker 1503 fails to close

Diesel test

Diesel maintenance

Total

$$
\begin{array}{r}
q(\text { NET })=1.0 \times 10^{-3} \\
3 \times 10^{-2} \\
1.0 \times 10^{-3} \\
2 \times 10^{-3} \\
q .5 \times 10^{-3} \\
q(E D G)=\frac{6 \times 10^{-2}}{}
\end{array}
$$

DETAILED ANALYSIS: $\lambda=\lambda(\mathrm{NET}) \cdot \mathrm{q}^{\prime}($ EDG $)+\lambda(\mathrm{MISC})$

\section{Loss of NET}

Diesel unavailable

Running diesel fails, not repaired

Average

Opens

Shorts

Double faults

Opens, shorts, double faults

Total

2) QB00: IP on 480-V LOAD CENTER 20B10

Unavailability at LOCA

Failure rate

MAJOR CONTRIBUTORS

Loss of NET and diesel fails to start

Shorts and opens to $20 \mathrm{~B} 10$

DETAILED ANALYSIS: $\lambda$

IP on $4160 \mathrm{~V} \mathrm{E} 12$

Opens

Shorts

Double faults

Total

$$
\begin{aligned}
\lambda(\mathrm{NET})= & 2.0 \times 10^{-5} \\
& 4.0 \times 10^{-2} \\
& \frac{6.3 \times 10^{-2}}{5.2 \times 10^{-2}} \\
\mathrm{q}^{9}(\mathrm{EDG})= & 1.0 \times 10^{-6} \\
& 1.1 \times 10^{-6} \\
& \frac{5.2 \times 10^{-9}}{2.1 \times 10^{-6}} \\
\lambda(\text { MISC })= & 3.1 \times 10^{-6}
\end{aligned}
$$

$Q=4.0 \times 10^{-5}$

$\lambda=1.2 \times 10^{-5}$

$Q=4.0 \times 10^{-5}$

$\lambda=8.7 \times 10^{-6}$

$$
\begin{aligned}
& 3.1 \times 10^{-6} \\
& 6.0 \times 10^{-6} \\
& 2.7 \times 10^{-6} \\
& 1.0 \times 10^{-9} \\
& \lambda=1.2 \times 10^{-5}
\end{aligned}
$$


Table E-2 (continued).

3) Q4A: IP On PUMP STRUCTURE MCC $00 B 62$

Unavailability at LOCA

$Q=4.0 \times 10^{-5}$

Failure rate

$\lambda=1.5 \times 10^{-5}$

MAJOR CONTRIBUTORS

Loss of NET and diesel fails to start

$Q=4.0 \times 10^{-5}$

IP on load center $20 \mathrm{~B} 10$

$\lambda=1.2 \times 10^{-5}$

DF.TAILED ANALYSIS: $\lambda$

IP on load center 20B10

Opens

Shorts

Total

$$
\begin{aligned}
& 1.2 \times 10^{-5} \\
& 3.0 \times 10^{-6} \\
& 3.0 \times 10^{-7} \\
& \lambda=1.5 \times 10^{-5}
\end{aligned}
$$

4) Q5A IP on DIESEL GEN MCC 00B53

Unavailability at LOCA

Failure rate

$Q=4.0 \times 10^{-5}$

$\lambda=1.5 \times 10^{-5}$

MAJOR CONTRIBUTORS

Loss of NET and diesel fails to slart

$Q=4.0 \times 10^{-5}$

IP on load center $20 \mathrm{~B} 10$

$\lambda=1.2 \times 10^{-5}$

DETAILED ANALYSIS: $\lambda$

IP on load center $20 B 10$

Opens

Shorts

Total.

$$
\lambda=\begin{array}{r}
1.2 \times 10^{-5} \\
3.0 \times 10^{-6} \\
3.0 \times 10^{-7} \\
\hline 1.5 \times 10^{-5}
\end{array}
$$

5) Q6A: IP on REACTOR AREA MCC $20 \mathrm{~B} 36$

Unavailability at LOCA

$\mathrm{Q}=4.0 \times 10^{-5}$

Failure rate

$\lambda=1.5 \times 10^{-5}$

MAJOR CONTRIBUTORS

Los of NET and diesel fails to s.tart

$\mathrm{Q}=4.0 \times 10^{-5}$

IP on load center $20 \mathrm{~B} 10$

$\dot{\lambda}=1.2 \times 10^{-5}$

DETAILED ANALYSIS: $\lambda$

IP on load center $20 \mathrm{~B} 10$

$1.2 \times 10^{-5}$

Opens

$3.0 \times 10^{-6}$

Shorts

Total

$\lambda=\frac{3.0 \times 10^{-7}}{1.5 \times 10^{-5}}$ 
Table E-2 (continued).

6) Q7A: IP on TURBINE AREA MCC 20B59

Unavailability at LOCA

$\mathrm{Q}=4.0 \times 10^{-5}$

Failure rate

$\lambda=1.5 \times 10^{-5}$

MAJOR CONTRIBUTORS

Loss of NET and diesel fails to start

$\mathrm{Q}=4.0 \times 10^{-5}$

IP on load center $20 \mathrm{~B} 10$

$\lambda=1.2 \times 10^{-5}$

DETAILED ANALYSIS: $\lambda$

IP on load center $20 \mathrm{~B} 10$

$1.2 \times 10^{-5}$

Opens

Shorts

Total

$3.0 \times 10^{-6}$

$\lambda=\frac{3.0 \times 10^{-7}}{1.5 \times 10^{-5}}$

7) Q9A: IP on DC PNL 2AD18

Unavailability at LOCA

Failure rate

$Q=1.0 \times 10^{-3}$

$\lambda=6.3 \times 10^{-6}$

MAJOR CONTRIBUTORS

IP from BATTERY

Loss of NET and BATTERY

$Q=1.0 \times 10^{-3}$

$\lambda=4.1 \times 10^{-6}$

DETAILED ANALYSIS: $Q=q(B A T T E R Y)$

IP from BATTERY

$1.0 \times 10^{-3}$

DETAILED ANALYSIS: $\lambda$

Loss of NET and BATTERY

$4.1 \times 10^{-6}$

Opens

Shorts

$2.0 \times 10^{-6}$

Double faults

$2.0 \times 10^{-7}$

Total

$$
\lambda=\frac{1.0 \times 10^{-12}}{6.3 \times 10^{-6}}
$$


Table E-2 (continued).

8) Q10A: IP on DC PNL 20D21

Unavailability at LOCA

$\mathrm{Q}=1.0 \times 10^{-3}$

Failure rate

$\lambda=3.4 \times 10^{-6}$

MAJOR CONTRIBUTORS

IP from BATTERY

Opens

$Q=1.0 \times 10^{-3}$

$\lambda=3.0 \times 10^{-6}$

DETAILED ANALYSIS: $\lambda=\lambda(\mathrm{BC}) \cdot \mathrm{q}(\mathrm{OL})+\lambda(9 \mathrm{~A})+\lambda(\mathrm{S})+\lambda(\mathrm{O})+\lambda(\mathrm{DF})$

IP from BATTERY charger

$\lambda(\mathrm{BC})=4.1 \times 10^{-5}$

DC overload: NON-ESF loads not removed ${ }^{a}$

$q(O L)=1.0 \times 10^{-3}$

Shorts on PNL 2 AD1 8

$\lambda(9 \mathrm{~A})=2.0 \times 10^{-7}$

Shorts on PNL 20D21

$\lambda(\mathrm{S})=2.0 \times 10^{-7}$

Opens

$\lambda(\mathrm{O})=3.0 \times 10^{-6}$

Double faults

$\begin{aligned} \lambda(\mathrm{DF}) & =1.0 \times 10^{-11} \\ \lambda & =3.4 \times 10^{-6}\end{aligned}$

Total

$$
\lambda=3.4 \times 10^{-6}
$$

${ }^{\mathrm{a}}$ Will cause failure in 4 to $8 \mathrm{hr}$ after battery charges is lost due to battery drain.

9) Q11A: IP on DC PNL 20D12

Unavailability at LOCA

$Q=1.0 \times 10^{-4}$

Failure rate

$\lambda=1.5 \times 10^{-5}$

MAJOR CONTRIBUTORS

LOSS of NET and DC overload

Loss of NET and either BATTERY overloaded

$Q=1.0 \times 10^{-4}$

$\lambda=6.2 \times 10^{-6}$

DETAILED ANALYSIS: $\lambda$

Loss of NET and either BATTERY overloaded

$6.2 \times 10^{-6}$

Shorts on $2 A D 18+$ OR -

$4.0 \times 10^{-7}$

Opens on $2 A D 18$ + OR -

Opens on $20 \mathrm{D} 12$

$4.0 \times 10^{-6}$

Shorts on 20D12

$4.0 \times 10^{-6}$

Double faults

$2.0 \times 10^{-7}$

Total

$\lambda=\frac{1.5 \times 10^{-9}}{1.5 \times 10^{-5}}$ 
Table E-2 (continued).

10) Q004: Loss of All AC Power

Unavailability at LOCA

$$
Q=1.0 \times 10^{-6}
$$

Failure probability

Cumulative, for outage lasting longe $r$

$\mathrm{p}=4.0 \times 10^{-7}$ at $24 \mathrm{hr}$

than miximum allowed outage

$\mathrm{p}=3.4 \times 10^{-6}$ at $1 \mathrm{mo}$

$\mathrm{p}=6.0 \times 10^{-6}$ at $4 \mathrm{mo}$

$\mathrm{p}=7.5 \times 10^{-6}$ at $9 \mathrm{mo}$

MAJOR CONTRIBUTOR

Loss of NET and all diesels fail to start

$$
Q=1.0 \times 10^{-6}
$$

(only critical path considered)

DETAILED ANALYSIS: $Q=q(N E T) \cdot q(4 D G)$

$$
\begin{aligned}
Q(N E T) & =1.0 \times 10^{-3} \\
q(2 D G)=q(3 D G)=q(4 D G) & =1.0 \times 10^{-3}
\end{aligned}
$$


APPENDIX F

PWR RESULTS

The PWR emergency power system was analyzed for insufficient power (IP). Representative quantitative results are given in Tables F-1 and F-2. 
Table F-1. Unavailability $(q)$ and effective failure rates $(\lambda)$ for the emergency power buses of a PWR.

\begin{tabular}{|c|c|c|c|c|c|c|c|}
\hline \multirow{2}{*}{$\begin{array}{l}\text { Fault tree } \\
\text { event }\end{array}$} & \multirow{2}{*}{$\begin{array}{c}\text { Event } \\
\text { description }\end{array}$} & \multirow{2}{*}{$\stackrel{q}{\text { Median }}$} & \multicolumn{2}{|c|}{$90 \%$ bounds } & \multirow{2}{*}{$\stackrel{\lambda}{\text { Median }}$} & \multicolumn{2}{|c|}{$90 \%$ bounds } \\
\hline & & & Lower & Upper & & Lower & Upper \\
\hline JN 04 & IP on Bus $34.5-5$ & $10^{-3}$ & $3 \times 10^{-4}$ & $3 \times 10^{-3}$ & $2.9 \times 10^{-5}$ & $2.9 \times 10^{-6}$ & $2.9 \times 10^{-4}$ \\
\hline $\mathrm{JP04}$ & IP on Bus $34.5-6$ & $10^{-3}$ & $3 \times 10^{-4}$ & $3 \times 10^{-3}$ & $2.9 \times 10^{-5}$ & $2.9 \times 10^{-6}$ & $2.9 \times 10^{-4}$ \\
\hline JA07 & $\begin{array}{l}\text { IP output on Bus or } \\
\text { BKR } 15 \mathrm{~J} 8\end{array}$ & $10^{-3}$ & $3 \times 10^{-4}$ & $3 \times 10^{-3}$ & $3.0 \times 10^{-5}$ & $3.0 \times 10^{-6}$ & $3.0 \times 10^{-4}$ \\
\hline JB07 & $\begin{array}{l}\text { IP output on Bus or } \\
\text { BKR } 15 \mathrm{H} 8\end{array}$ & $10^{-3}$ & $3 \times 10^{-4}$ & $3 \times 10^{-3}$ & $3.0 \times 10^{-5}$ & $3.0 \times 10^{-6}$ & $3.0 \times 10^{-4}$ \\
\hline JA00 & IP on Bus $4160-1 \mathrm{~J}$ & $4 \times 10^{-5}$ & $4 \times 10^{-6}$ & $4 \times 10^{-4}$ & $3.4 \times 10^{-6}$ & $3.4 \times 10^{-7}$ & $3.4 \times 10^{-5}$ \\
\hline JBOO & IP on Bus $4160-1 \mathrm{H}$ & $4 \times 10^{-5}$ & $4 \times 10^{-6}$ & $4 \times 10^{-4}$ & $3.4 \times 10^{-6}$ & $3.4 \times 10^{-7}$ & $3.4 \times 10^{-5}$ \\
\hline $\mathrm{JC} 00$ & IP on Bus $480-1 \mathrm{~J}$ & $4 \times 10^{-5}$ & $4 \times 10^{-6}$ & $4 \times 10^{-4}$ & $1.1 \times 10^{-5}$ & $1.1 \times 10^{-6}$ & $1.1 \times 10^{-4}$ \\
\hline JD00 & IP on Bus $480-1 \mathrm{H}$ & $4 \times 10^{-5}$ & $4 \times 10^{-6}$ & $4 \times 10^{-4}$ & $1.1 \times 10^{-5}$ & $1.1 \times 10^{-6}$ & $1.1 \times 10^{-4}$ \\
\hline JEOO & IP on Bus MCC $1 \mathrm{~J} 1-1$ & $4 \times 10^{-5}$ & $4 \times 10^{-6}$ & $4 \times 10^{-4}$ & $1.4 \times 10^{-5}$ & $1.4 \times 10^{-6}$ & $1.4 \times 10^{-4}$ \\
\hline JF00 & IP on Bus MCC $1 \mathrm{H} 1-1$ & $4 \times 10^{-5}$ & $4 \times 10^{-6}$ & $4 \times 10^{-4}$ & $1.4 \times 10^{-5}$ & $1.4 \times 10^{-6}$ & $1.4 \times 10^{-4}$ \\
\hline JG00 & IP on Bus MCC $1 \mathrm{~J} 1-2$ & $4 \times 10^{-5}$ & $4 \times 10^{-6}$ & $4 \times 10^{-4}$ & $1.3 \times 10^{-5}$ & $1.3 \times 10^{-6}$ & $1.3 \times 10^{-4}$ \\
\hline $\mathrm{JH} 00$ & IP on Bus MCC $1 \mathrm{H} 1-2$ & $4 \times 10^{-5}$ & $4 \times 10^{-6}$ & $4 \times 10^{-4}$ & $1.3 \times 10^{-5}$ & $1.3 \times 10^{-6}$ & $1.3 \times 10^{-4}$ \\
\hline JJ0O & IP on Bus $D C-1 B$ & $10^{-6}$ & $10^{-7}$ & $10^{-5}$ & $1.2 \times 10^{-6}$ & $1.2 \times 10^{-7}$ & $1.2 \times 10^{-5}$ \\
\hline JK00 & IP on Bus DC-1A & $10^{-6}$ & $10^{-7}$ & $10^{-5}$ & $1.2 \times 10^{-6}$ & $1.2 \times 10^{-7}$ & $1.2 \times 10^{-5}$ \\
\hline JV01 & IP on vital Bus $1-I$ & $10^{-6}$ & $10^{-7}$ & $10^{-5}$ & $1.7 \times 10^{-5}$ & $1.7 \times 10^{-6}$ & $1.7 \times 10^{-4}$ \\
\hline JV03 & IP on vital Bus $1-$ III & $4 \times 10^{-5}$ & $4 \times 10^{-6}$ & $4 \times 10^{-4}$ & $1.7 \times 10^{-5}$ & $1.7 \times 10^{-6}$ & $1.7 \times 10^{-4}$ \\
\hline J000 & $\begin{array}{l}\text { IP to ESF system } \\
\text { during LOCA }\end{array}$ & $10^{-5}$ & $10^{-6}$ & $10^{-4}$ & & & \\
\hline
\end{tabular}


Table F-2. Quantitative results for fault tree analysis on train A.

1) JP04: IP on 34.5-6 BUS

Unavailability at LOCA

Failure rate

MAJOR CONTRIBUTORS

Loss of offsite power at LOCA

(LOSS of NET)

Loss of NET after LOCA

DETAILED ANALYSIS: $\lambda$

LosS of NET

Opens

Transformer shorts

Other shorts

Double faults

Total

2) JB07: Loss of Offsite Power to BUS 4160-1H

Availability at LOCA

Failure rate

MAJOR CONTRIBUTORS

Loss of NET

Loss of NET after LOCA

DETAILED ANALYSIS: $Q$

Loss of NET

Operator inadvertently opens

breake $15 \mathrm{H} 8$

Total

DETAILED ANALYSIS: $\lambda$

Opens

Transformer shorts

Other shorts

Double faults

Loss of NET

Total
$\mathrm{Q}=1.0 \times 10^{-3}$

$\lambda=2.9 \times 10^{-5}$

$Q=1.0 \times 10^{-3}$

$\lambda=2.0 \times 10^{-5}$

$2.0 \times 10^{-5}$

$4.0 \times 10^{-6}$

$4.0 \times 10^{-6}$

$8.0 \times 10^{-7}$

$5.9 \times 10^{-9}$

$\lambda=\overline{2.9 \times 10^{-5}}$

$\mathrm{Q}=1.1 \times 10^{-3}$

$\lambda=3.0 \times 10^{-5}$

$Q=1.0 \times 10^{-3}$

$\lambda=2.0 \times 10^{-5}$

$1.0 \times 10^{-3}$

$1.0 \times 10^{-4}$

$Q=1.1 \times 10^{-3}$

$$
\begin{aligned}
& 8.0 \times 10^{-6} \\
& 1.0 \times 10^{-6} \\
& 7.0 \times 10^{-7} \\
& 3.0 \times 10^{-9} \\
\lambda= & \frac{2.0 \times 10^{-5}}{3.0 \times 10^{-5}}
\end{aligned}
$$


Table F-2 (continued).

3) JB00: IP on BUS $41601 \mathrm{H}$

Unavailability at LOCA

$Q=4.1 \times 10^{-5}$

Failure rate

$\lambda=3.4 \times 10^{-6}$

MAJOR CONTRIBUTORS

Loss of NET and diesel fails to start

$\mathrm{Q}=3.0 \times 10^{-5}$

Shorts and opens

$\lambda=2.4 \times 10^{-6}$

DETAILED ANALYSIS: $Q=q(N E T) \cdot q(E D G)$

Loss of offsite power (JB07)

Diesel fails to start

$$
\begin{aligned}
\mathrm{q}(\mathrm{NET})= & 1.1 \times 10^{-3} \\
& 3.0 \times 10^{-2} \\
& 1.0 \times 10^{-3} \\
& 1.0 \times 10^{-3} \\
& \frac{5.2 \times 10^{-3}}{2.7 \times 10^{-2}} \\
\mathrm{Q}=\mathrm{q}(\mathrm{NET}) \cdot \mathrm{q}(\mathrm{EDG})= & 4.0 \times 10^{-5}
\end{aligned}
$$

Battery open, $15 \mathrm{H} 3$ cannot close

$15 \mathrm{H} 3$ fails to close

Diesel maintenance $(45 \mathrm{hr} / \mathrm{yr})$

DETAILED ANALYSIS: $\lambda=\lambda(\mathrm{NET}) \cdot \mathrm{q}(\mathrm{EDG})+\lambda(\mathrm{NET}) \cdot \tau(\mathrm{NET}) \cdot \lambda(\mathrm{EDG})+\lambda(\mathrm{HDW})$

LOSS of NET (JB07)

NET mean repair time

Diesel fails

Opens

Shorts

Double faults

Total

4) JD00: IP on BUS 480-IH

Unavailability at LOCA

Failure rate

MAJOR CONTRIBUTORS

IP on $41601 \mathrm{H}$ (JB00)

IP on $41601 \mathrm{H}$ and opens

DETAILED ANALYSIS: $\lambda$

IP from $41601 \mathrm{H}$ (JB00)

Opens

Shorts

Double faults

Total
$\lambda(\mathrm{NET})=3.0 \times 10^{-5}$

$\tau(\mathrm{NET})=1.0 \mathrm{hr}$

$\lambda(\mathrm{EDG})=3.0 \times 10^{-3}$

$$
\begin{aligned}
& 2.0 \times 10^{-6} \\
& 4.0 \times 10^{-7} \\
& \lambda(\mathrm{HDW})=\frac{3.4 \times 10^{-9}}{2.4 \times 10^{-6}}
\end{aligned}
$$

$Q=4.1 \times 10^{-5}$

$\lambda=1.1 \times 10^{-5}$

$\mathrm{Q}=4.1 \times 10^{-5}$

$\lambda=9.4 \times 10^{-6}$ 
Table H'-2 (continued).

5) JF00: IP on MCC 1H1-1

Unavailability at LOCA

$Q=4.1 \times 10^{-5}$

Failure rate

$\lambda=1.4 \times 10^{-5}$

MAJOR CONTRIBUTORS

IP on $41601 \mathrm{H}(\mathrm{JBOO})$

$Q=4.1 \times 10^{-5}$

IP. on $4801 \mathrm{H}$ (JD00)

$\lambda=1.1 \times 10^{-5}$

DETAILED ANALYSIS: $\lambda$

IP from $4801 \mathrm{H}$ (JDOO).

Opens

Shorts

Double faults

Total

$$
\begin{aligned}
& 1.1 \times 10^{-5} \\
& 3.0 \times 10^{-6} \\
& 2.0 \times 10^{-7} \\
\quad & \frac{8.7 \times 10^{-9}}{1.4 \times 10^{-5}}
\end{aligned}
$$

6) JH00: IP on MCC IHI-2

Unavailability at LOCA

$Q=4.1 \times 10^{-5}$

Failure rate

$\lambda=1.3 \times 10^{-5}$

MAJOR CONTRIBUTORS

IF on $4160 \mathrm{IH}$ (JBO0)

$Q=4.1 \times 10^{-5}$

IP on $480 \mathrm{IH}$ (JD00)

$\lambda=1.1 \times 10^{-5}$

DETAILED ANALYSIS: $\lambda$

IP from $480 \mathrm{IH}$ (JD00)

Opens

Shorts

Double faults'

Total

$$
\begin{aligned}
& 1.1 \times 10^{-5} \\
& 2.0 \times 10^{-6} \\
& 4.0 \times 10^{-7} \\
& 1.4 \times 10^{-8} \\
& \lambda=\overline{1.3 \times 10^{-5}}
\end{aligned}
$$


7) JK00: IP on BUS DC $1 \mathrm{~A}$

Unavailability at LOCA

$\mathrm{Q}=1.1 \times 10^{-6}$

Failure rate

$\lambda=1.2 \times 10^{-6}$

MAJOR CONTRIBUTORS

LOSS of NET and BATTERY

$Q=1.0 \times 10^{-6}$

Opens

$\lambda=1.0 \times 10^{-6}$

DETAILED ANALYSIS: $Q=q($ OFFSITE PÓWER) $q$ (BATTERY)

OFFSITE POWER (JB07)

BATTERY

$\mathrm{q}\left(\right.$ OF HSITE POWER) $=1.1 \times 10^{-3}$

$\mathrm{q}(\mathrm{BATTERY})=1.0 \times 10^{-3}$

DETAILED ANALYSIS: $\lambda=\lambda($ JFOO $) \cdot q($ BATTERY $)+$

$\lambda(\mathrm{JFO0}) \cdot \tau(\mathrm{JFO0}) \cdot \lambda(\mathrm{BATTFRY})+\lambda(\mathrm{HDW})$

IP on BUS MCC $1 \mathrm{H} 1-1$ (JF00)

$\lambda(\mathrm{JFO0})=1.4 \times 10^{-5}$

Mean repair time

$\tau(\mathrm{JFOO}) \simeq 6.5 \mathrm{hr}$

BATTERY open

$\lambda($ BATTERY $)=1.0 \times 10^{-6}$

Opens

Shurts

Double fault.s

Total

$$
\begin{aligned}
& 2.0 \times 10^{-7} \\
& \lambda(\mathrm{HDW})=\frac{3.3 \times 10^{-8}}{1.2 \times 10^{-6}}
\end{aligned}
$$

8) JV01: IP on Vital BUS 1-I

Unavailability at LOCA

$Q=1.1 \times 10^{-6}$

Failure rate

$\lambda=1.7 \times 10^{-5}$

MAJOR CONTRIBUTORS

IP on DC. $1 \mathrm{~A}$ (JK00)

$Q=1.1 \times 10^{-6}$

Inverter: short

$\lambda=1.0 \times 10^{-5}$

DETAILED ANALYSIS: $\lambda$

IP on DClA (JKOO)

$1.2 \times 10^{-6}$

Opens

$5.0 \times 10^{-6}$

Shorts

$4.0 \times 10^{-7}$

Inverter short

$1.0 \times 10^{-5}$

Double faults

$\lambda=\frac{2.6 \times 10^{-9}}{1.7 \times 10^{-5}}$

Total 
Table F-2 (continued).

9) JV03: IP on Vital BUS 1-III

Unavailability at LOCA

Failure rate

$$
\begin{aligned}
& Q=4.1 \times 10^{-5} \\
& \lambda=2.0 \times 10^{-5}
\end{aligned}
$$

MAJOR CONTRIBUTORS

IP on $41601 \mathrm{H}$ (JB00)

IP on $\mathrm{MCC} 1 \mathrm{H} 1-1$ (JFO0)

$Q=4.1 \times 10^{-5}$

$\lambda=1.4 \times 10^{-5}$

DETAILED ANALYSIS: $\lambda$

IP on MCC 1H1-1 (JFO0)

$$
1.4 \times 10^{-5}
$$

Opens

Shorts

Double faults

Total

$$
5.0 \times 10^{-6}
$$$$
1.4 \times 10^{-6}
$$$$
2.6 \times 10^{-9}
$$

$\lambda=\frac{2.0 \times 10^{-5}}{2.0 \times 10^{-9}}$

10) J000: IP to ESF Systems During LOCA

Unavailability at LOC.A

Failure probability, cumulative, $p=p_{1} p_{2}$,

for outage lasting longer than

maximum allowed outage

\section{RTAJOR CONTRIBUTORS}

Loss of NET and 2 diesel.s fail to start

DETAILED ANALYSIS: $Q$

83 other critical paths

DETAILED ANALYSIS: $p$

83 other critical paths

$$
\begin{aligned}
& Q=1.0 \times 10^{-5} \\
& p=5.2 \times 10^{-6} \text { at } 24 \mathrm{hr} \\
& p=5.5 \times 10^{-5} \text { at } 1 \mathrm{mo} \\
& p=7.5 \times 10^{-5} \text { at } 4 \mathrm{mo} \\
& p=8.0 \times 10^{-5} \text { at } 9 \mathrm{mo}
\end{aligned}
$$

$$
\begin{aligned}
Q & =1.0 \times 10^{-5} \\
p_{1} & =4.8 \times 10^{-6} \text { at } 24 \mathrm{hr} \\
p_{1} & =4.8 \times 10^{-5} \text { at } 1 \mathrm{mo} \\
p_{1} & =6.4 \times 10^{-5} \text { at } 4 \mathrm{mo} \\
p_{1} & =6.8 \times 10^{-5} \text { at } 9 \mathrm{mo}
\end{aligned}
$$

$$
Q<10^{-7}
$$

$$
\begin{aligned}
& \mathrm{p}_{2}=4.0 \times 10^{-7} \text { at } 24 \mathrm{hr} \\
& \mathrm{p}_{2}=6.5 \times 10^{-6} \text { at } 1 \mathrm{mo} \\
& \mathrm{p}_{2}=1.1 \times 10^{-5} \text { at } 4 \mathrm{mo} \\
& \mathrm{p}_{2}=1.2 \times 10^{-5} \text { at } 9 \mathrm{mo}
\end{aligned}
$$

NOTICl:

"Tlis report was prepured as an account of work sponsored by the United States Government. Neither the Unitel States nor the Unitul States Alomic Inergy Commission, nor any of their

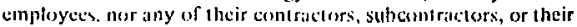
employecs. makes any warrants. expocs or implied, or assumes any legal liability or responsilibily for tle inceuracy. completentess or uscledness of any information, apparal us, preduct or process disclesed, or represents that its use would not infringe privalclynwned riglt:s."

$\mathrm{JKP} / \mathrm{cb}$ 